Estudios sobre armas antiguas, arte militar $\mathrm{y}$ vida cultural en oriente y occidente

XXXIX (2019), pp. 19-43

ISSN: 0436-029X

https://doi.org/10.3989/gladius.2019.02

\title{
PUIG CASTELLAR DE BIOSCA (LLEIDA). UNA FORTIFICACIÓN ROMANA DEL SIGLO II A. C. EN EL NORESTE DE LA HISPANIA CITERIOR*
}

\author{
PUIG CASTELLAR (BIOSCA). A ROMAN MILITARY FORTRESS \\ OF THE II CENTURY BC IN NE HISPANIA CITERIOR
}

POR

\author{
Joaquim Pera Isern ${ }^{* *}$, Esther Rodrigo Requena ${ }^{* * *}$, Núria Romaní Sala ${ }^{* * * *}$ \\ y CÉSAR CARRERAs MonforT ${ }^{* * * * *}$
}

\section{Resumen - AbStRact}

Las recientes excavaciones arqueológicas efectuadas en el cerro de Puig Castellar de Biosca (Lleida) han dejado al descubierto los vestigios de un establecimiento militar romano, tipo castellum, singular por sus características tipológicas y su temprana cronología en el marco hispánico. El asentamiento muestra un amplio dominio visual sobre el territorio inmediato; está delimitado por una muralla defensiva con torres. En su interior destaca un gran edificio, erigido en el punto más elevado del recinto, que muestra varias dependencias distribuidas en torno a un patio central que a su vez dispone de una gran cisterna excavada en la roca. También se han localizado algunas dependencias auxiliares cerca del edificio principal y otras adosadas a la cara interna de la muralla, así como una zona con gran actividad metalúrgica de hierro. La gran cantidad de material cerámico recuperado, sobre todo de importación, con un horizonte cronológico bien definido entre el 180 y el 120 a. C., así como las técnicas constructivas y decorativas identificadas en los edificios, nos permiten afirmar que se trata de un complejo militar y administrativo de los primeros decenios de la conquista romana de Hispania.

The recent archaeological excavations undertaken at the hill of Puig Castellar (Biosca, Lleida) have revealed the remains of singular Roman military settlement for its typological features and early dating. A solid defence wall with towers and visual control of the nearby territory surrounds the site. Inside, Romans built a large building at the highest point, which records a number of auxiliary rooms around a central courtyard. The courtyard included a rock cut cistern. Besides, there are other buildings close to the main building and others accommodated to the inner face of the surrounding defence wall as well as an area with great iron metallurgical activity. The large amount of Italian pottery with a well-dated horizon between 180-120 BCE as well as constructive and decorative techniques identified in the buildings reveal a possible military and administrative complex of the earlier decades of Roman conquest in Hispania.

* Las excavaciones en Puig Castellar de Biosca se inscriben en un amplio proyecto de investigación centrado en el estudio de los primeros modelos de ocupación romana en Hispania, dirigido por el equipo de arqueología clásica de la Universidad Autónoma de Barcelona en colaboración con el Patronat d'Arqueologia de Guissona y el Institut Català d'Arqueologia Clàssica (ICAC). Los trabajos han sido subvencionados por el MINECO-FEDER (HAR2015-64601-C3$1-R)$ y la Generalitat de Catalunya (2014/100904).

** Universidad Autónoma de Barcelona, Dep. de Ciencias de la Antigüedad y la Edad Media, joaquim.pera@uab. cat / ORCID iD: https://orcid.org/0000-0002-5360-5447

${ }^{* * *}$ Universidad Autónoma de Barcelona, Dep. de Ciencias de la Antigüedad y la Edad Media / ICAC. Institut Català d'Arqueologia Clàssica, Tarragona, esther.rodrigo@uab.cat / ORCID iD: https://orcid.org/0000-0003-4771-1216

***** Universidad Autónoma de Barcelona, Dep. de Ciencias de la Antigüedad y la Edad Media / ICAC. Institut Català d'Arqueologia Clàssica, Tarragona, nuria.romani@uab.cat / ORCID iD: https://orcid.org/0000-0002-5942-6992

****** Universidad Autónoma de Barcelona, Dep. de Ciencias de la Antigüedad y la Edad Media, cesar.carreras@uab. cat / ORCID iD: https://orcid.org/0000-0003-4300-9470 
Palabras Clave - Keywords

Conquista romana; romanización; castellum; Cataluña; cerámica campaniense.

Roman conquest; romanisation; castellum; Catalonia; Campanian black-gloss ware.

\section{Cómo citar este artículo / Citation}

Pera Isern, J.; Rodrigo Requena, E.; Romaní Sala, N. y Carreras Monfort, C. (2019): «Puig Castellar de Biosca (Lleida). Una fortificación romana del siglo II a. C. en el noreste de la Hispania Citerior». Gladius, XXXIX: 19-43. https://doi.org/10.3989/gladius.2019.02

\section{SITUACIÓN Y ANTECEDENTES}

Puig Castellar es el topónimo donde se ubica el yacimiento, aunque cuenta con otras denominaciones como: La Guixera de Talteüll o Guixot de la Peixera. Está situado en el término municipal de Biosca, comarca de la Segarra, provincia de Lleida (coordenadas UTM: 362048.953, 4631916.247). Se encuentra en un cerro de poca altura situado en la confluencia de tres cursos fluviales, actualmente muy estacionales: la Riera de Biosca al norte; el río Llobregós, afluente del Segre, y la Riera de Massoteres, al sur (Fig. 1).

La vertiente norte que se alza sobre la Riera de Biosca es muy pronunciada y constituye una defensa natural que hace imposible el acceso desde ese sector. Las vertientes oeste y sur descienden suavemente hasta encontrar los barrancos que conducen hasta el río Llobregós,

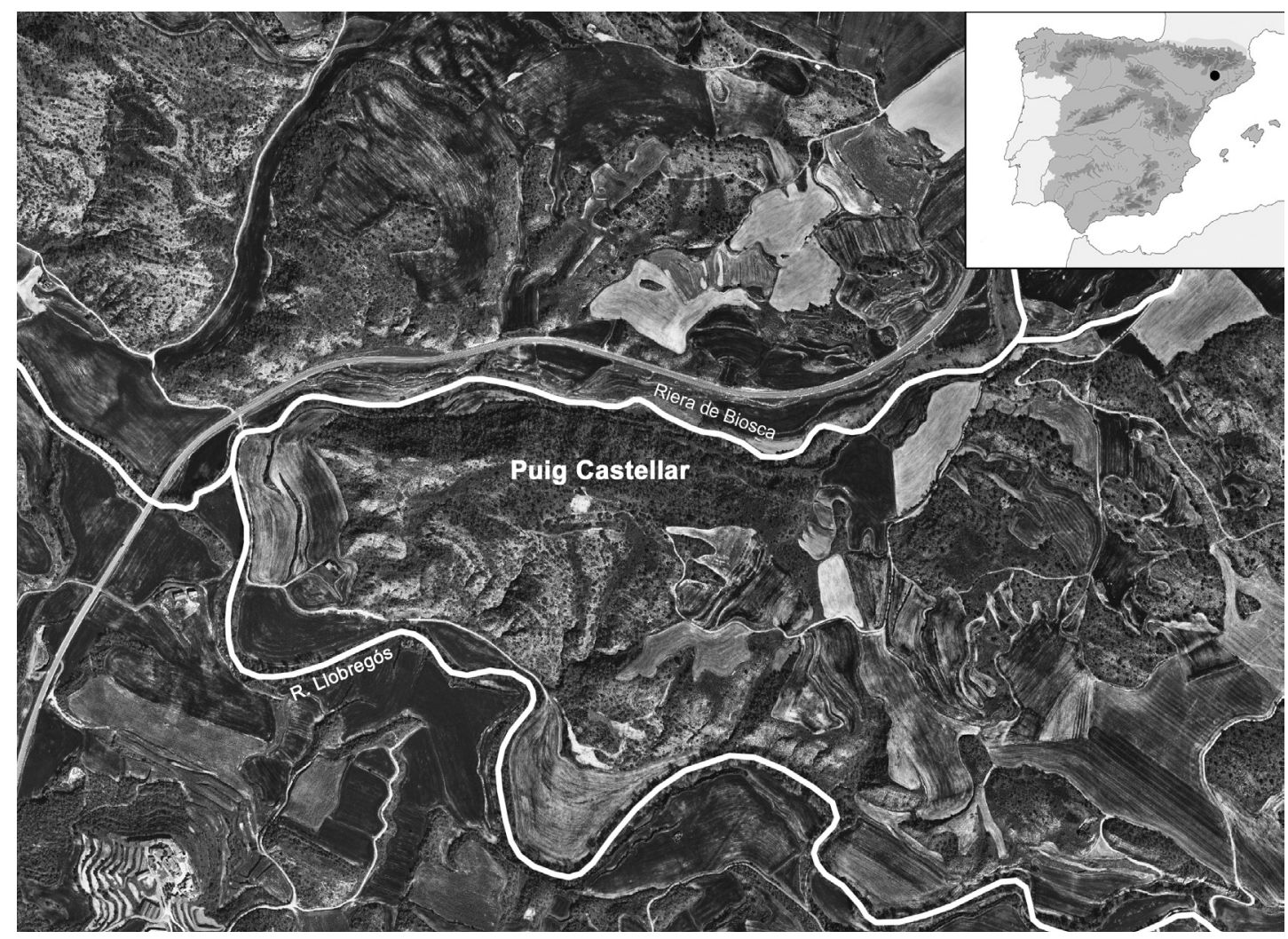

Figura 1. Situación del cerro de Puig Castellar de Biosca (ICC). 
en tanto que la vertiente este muestra una ladera más suave y es donde presumiblemente se localizaría el acceso al yacimiento.

El cerro de Puig Castellar tiene una composición geológica muy particular consistente en un afloramiento de rocas evaporíticas (yesos), unas formaciones geológicas que encontramos también en otros cerros que jalonan el curso del Llobregós. El terreno es pobre en nutrientes, un factor que ha favorecido el desarrollo de una vegetación rala de tipo arbustivo y matorral, lo que ha contribuido a la preservación del yacimiento a lo largo de los siglos debido a su escaso interés agrícola.

Desde la cima del cerro se dispone de un amplio dominio visual hacia los cuatro vientos, especialmente sobre el valle del río Llobregós, que constituye una vía natural de comunicación entre la zona de la Alta Segarra (Calaf-Els Prats de Rei) y el río Segre, afluente del Ebro; esta situación confiere al yacimiento de Puig Castellar una posición estratégica privilegiada para el control de esta ruta hacia el interior del país. También se controlan visualmente los pasos naturales que conducen hacia la comarca del Solsonés y el acceso a la subcomarca de Guissona, donde se emplazará posteriormente la ciudad romana de Iesso, situada solo a $6 \mathrm{~km}$.

En la década de los años setenta del siglo pasado el yacimiento había sido frecuentado por aficionados a la arqueología que habían efectuado excavaciones incontroladas, acciones que dejaron al descubierto algunos muros y un pavimento de terrazo, hoy totalmente desintegrado. De este período también hemos podido localizar cerámicas y monedas en pequeñas colecciones particulares: dos cuadrantes de Kese y Arse (primera mitad y último tercio de siglo II a. C., respectivamente). En los últimos años el yacimiento había sido sometido a un continuado expolio por parte de buscadores de metales, actividades atenuadas desde que se iniciaron las

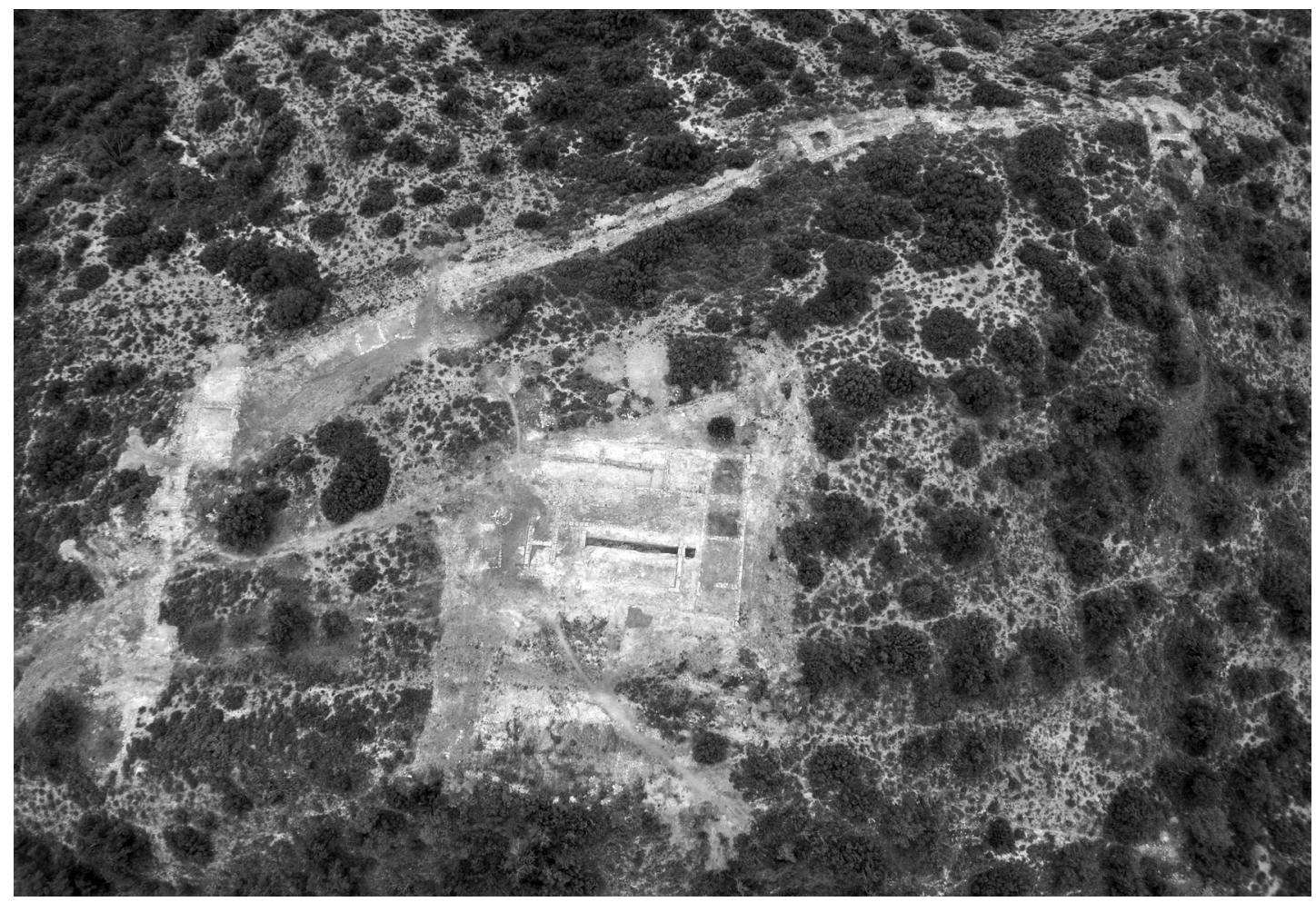

Figura 2. Vista aérea de Puig Castellar, delimitado por su muralla perimetral torreada (Sector C). En el punto más elevado del cerro, el edificio principal (Sector B) (Fotografía Equipo UAB). 


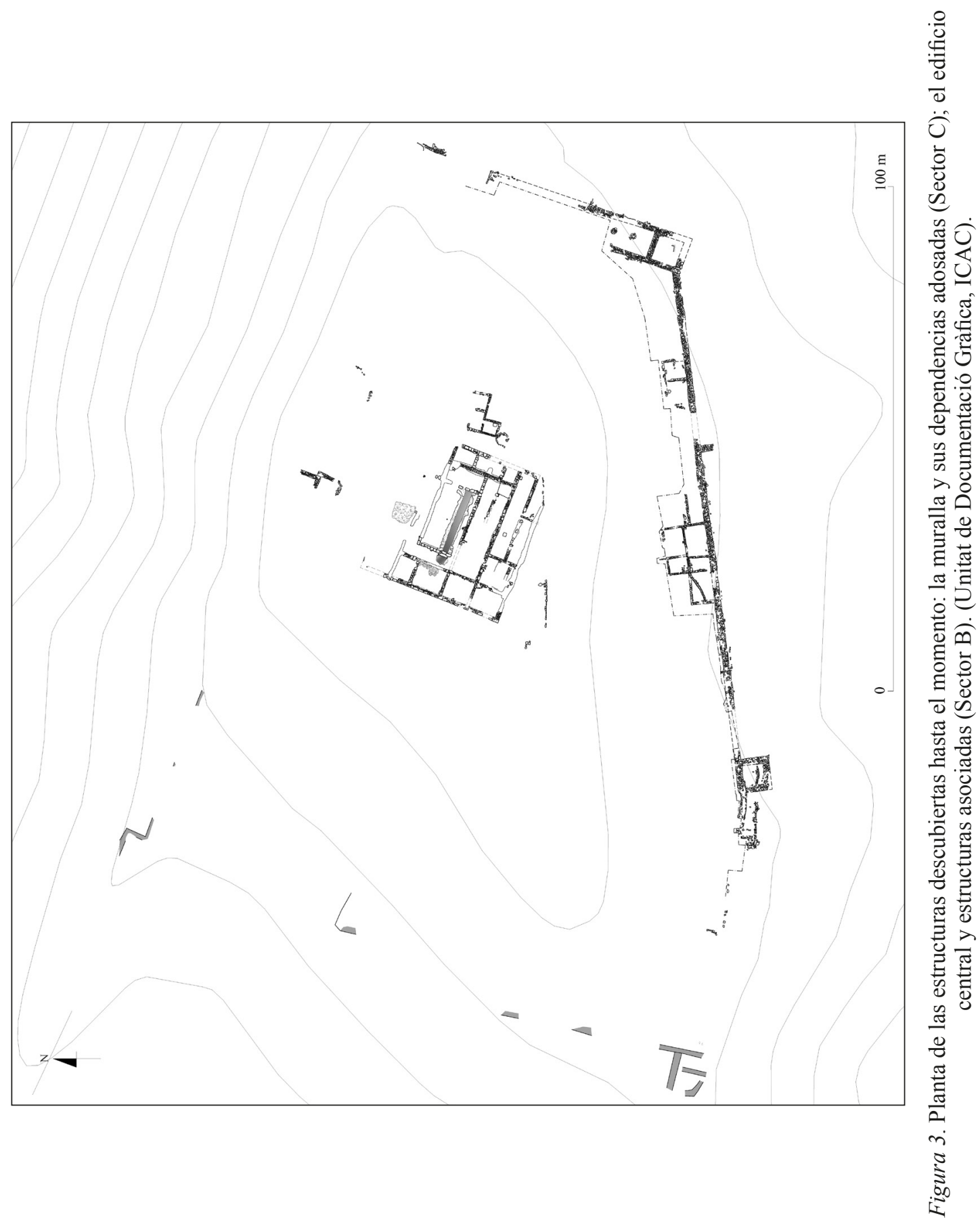


excavaciones en 2012. La existencia de este yacimiento era conocida desde hacía varias décadas y había sido catalogado erróneamente en la bibliografía como un poblado ibérico (Pita, 1954; Camps, 1960: 31; Boleda, 1976: 20; Rovira, 1979: 219; Pera, 1993; Rodrigo, 2006), sin más argumentos para sustentar esta adscripción cultural que los de su situación en altura, la presencia de cerámicas de barniz negro y pintadas de tradición ibérica, así como abundantes fragmentos de ánfora de tipo ibérico e itálico. Ha sido a partir de las primeras excavaciones de carácter científico efectuadas en el yacimiento que se cuestiona abiertamente la adscripción ibérica tradicional y se propone una nueva lectura interpretativa, no exenta de posibles matizaciones posteriores a medida que vayamos avanzando en el proyecto de excavación. A día de hoy los resultados arqueológicos aportados por las primeras campañas de excavación refuerzan una nueva interpretación para el yacimiento, en la línea de considerar esta instalación como un enclave romano; una instalación que, por su tipología, cronología y sobre todo, por la cantidad y variedad de importaciones documentadas, hemos de relacionar necesariamente con un asentamiento de tipo militar, un castellum (Figs. 2 y 3 ).

\section{EL EDIFICIO PRINCIPAL. DESCRIPCIÓN}

La excavación de la parte superior del cerro de Puig Castellar ha permitido identificar los restos del edificio principal que presidía el asentamiento (Fig. 4). Tras haber extraído los niveles superficiales de tipo vegetal, quedaron inmediatamente a la vista los cimientos de las paredes que conformaban el edificio, así como algunas porciones de pavimentos pertenecientes a las estancias, la mayoría de estos en un estado de extrema degradación debido a la acción

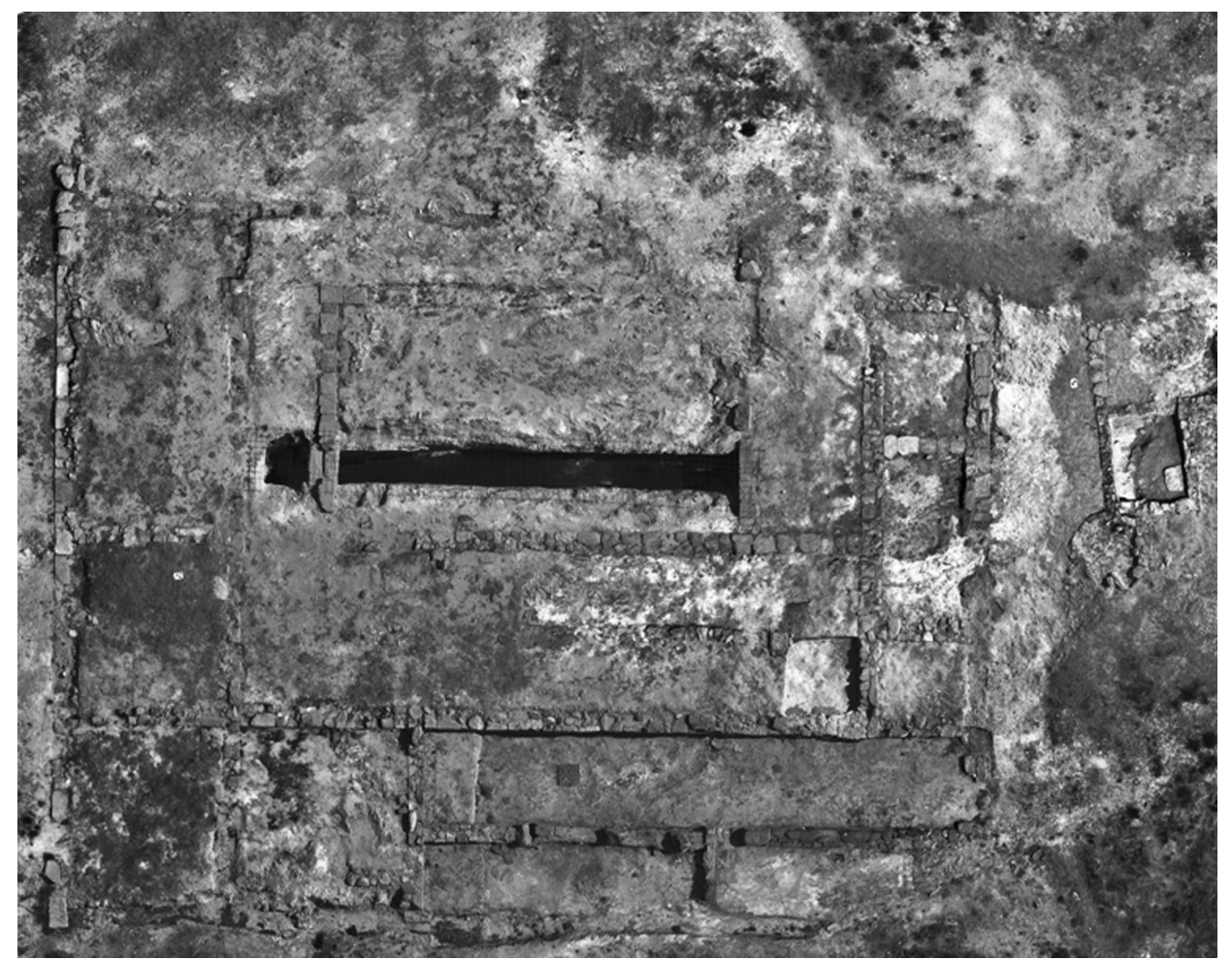

Figura 4. Vista aérea del edificio principal y sus dependencias asociadas (Fotografía Equipo UAB). 
destructiva de raíces y de la propia erosión natural. Asimismo, se puso en evidencia la escasa estratigrafía arqueológica conservada y el arrasamiento de muros y pavimentos; como muestra de ello, cabe indicar que en el interior de muchas de las estancias apareció directamente el terreno geológico formado por los yesos naturales. En algunos tramos de muro incluso ha desaparecido la piedra de los cimientos, siendo posible recuperar el trazado a partir del negativo dejado por sus trincheras de expolio. A pesar de estos problemas hemos podido completar la planta del edificio en su conjunto y su distribución interna de una forma bastante precisa.

Se define un gran edificio de planta cuadrada, de 30,2 $\times 29,7 \mathrm{~m}$ aproximadamente (Fig. 5), diseñado a partir de una modulación que sigue un patrón romano $(100 \times 100$ pies romanos): estamos frente a un edificio de dimensiones considerables (en torno a los $900 \mathrm{~m}^{2}$ ), con

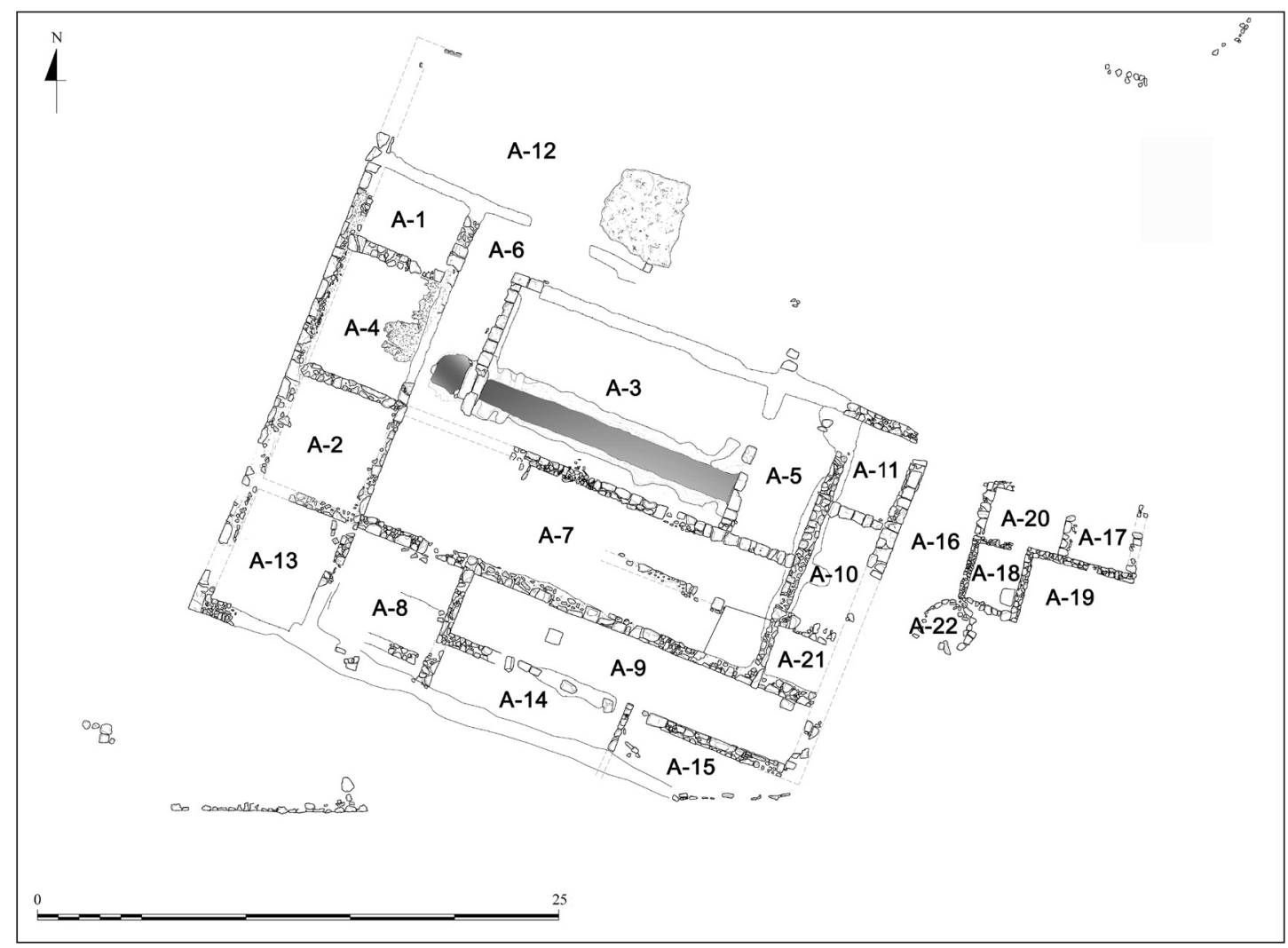

Figura 5. Relación de los ámbitos documentados en el edificio principal (Unitat de Documentació Gràfica, ICAC).

habitaciones articuladas en torno a un gran patio central (ámbito 3), enmarcado en dos de sus laterales (alas oeste y norte) por un corredor, posiblemente porticado (ámbito 6). Alrededor de estos espacios se distribuyen las catorce habitaciones documentadas. A pesar de la regularidad que en sus dimensiones exteriores muestra la planta general del edificio, llama la atención que en su distribución interior las estancias presenten dimensiones diferentes que van de los $52 \mathrm{~m}^{2}$ del ámbito 7 a los $12 \mathrm{~m}^{2}$ del ámbito 11. Por lógica constructiva algunas de estas habitaciones debieron tener el acceso desde el corredor y el patio, aunque no los hayamos podido identificar claramente al haber desaparecido los alzados de los muros y, en consecuencia, los correspon- 
dientes portales. Las habitaciones situadas en el ala sur, que corresponden a los ámbitos 9,14 y 15 , se sitúan en una cota de nivel más baja que el resto $(80 \mathrm{~cm})$; esto obedece a una solución arquitectónica que permite superar el desnivel original de la colina a que nos hemos referido anteriormente.

El elemento estructural en torno al cual se articula el edificio es el ámbito 3, un amplio patio central de $97 \mathrm{~m}^{2}$. El pavimento original era de tierra compactada y apareció muy degradado, quedando a la vista en muchos tramos el nivel geológico formado por yesos. De los muros que delimitaban el patio y las habitaciones solamente se conservan una o dos hiladas de piedra de la cimentación y, en algunos tramos, estos cimientos han desparecido totalmente, dejando al descubierto las trincheras de expolio de los muros; a partir de estos negativos se ha podido recomponer la planta original del edificio. En el transcurso de la excavación del patio fue identificada una franja de tierra de tonalidad marrón y composición arcillosa que contrastaba con el color blanquecino predominante del substrato geológico; por su posición y dimensiones se intuyó que esta franja podía ser indicativa de la existencia de una cisterna (Fig. 6), una infraes-

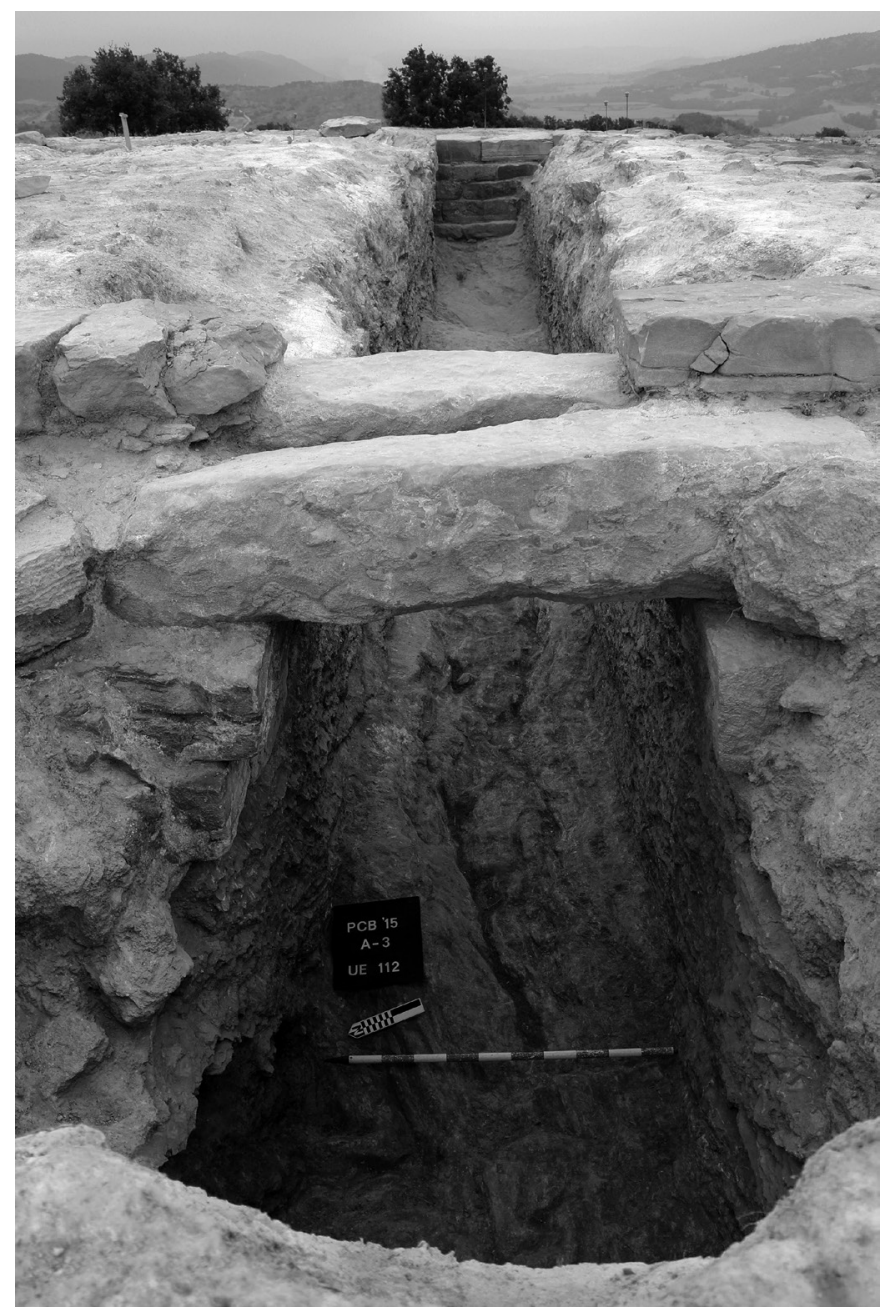

Figura 6. Gran cisterna recortada en la roca, en el lateral sur del patio del edificio principal. En primer término, el punto de extracción de agua; al fondo, muro de sillares de cierre de la cisterna (Fotografía Equipo UAB). 
tructura necesaria en este tipo de asentamientos y presente en otros establecimientos situados en altura con características similares: Can Tacó (Rodrigo et alii, 2013: 222-223), Sant Miquel de Sorba (Asensio et alii, 2014: 107) y Olérdola (Molist, 2008: 605), por citar algunos ejemplos contemporáneos. La excavación confirmó plenamente esta hipótesis: se trata de una gran cisterna rectangular excavada en la roca natural que, al contrario de lo que suele ser habitual, no presentaba ningún tipo de revestimiento hidráulico para su impermeabilización; posteriormente se ha podido comprobar que las características geológicas del subsuelo hacen innecesario un revoque parietal. Únicamente en su límite oriental la cisterna está cerrada por un sólido muro construido con grandes sillares, construcción que a su vez sirve de cimentación del muro de cierre del patio por este lado. La cisterna mide $13 \mathrm{~m}$ de longitud y una anchura que oscila entre $2,15 \mathrm{~m}$. y 2,80 m en su parte superior, aunque se va estrechando ligeramente a mayor profundidad. El fondo es irregular, entre los 1,5 $\mathrm{m}$ y $\operatorname{los} 2,45 \mathrm{~m}$. de profundidad; con estos datos se ha podido estimar una capacidad aproximada de $35 \mathrm{~m}^{3}$ (35.000 litros). El ensanchamiento de la parte superior y la presencia, a intervalos regulares, de recortes en el terreno de ambos lados de la zanja, se han interpretado como los encajes para las vigas que necesariamente soportarían la cubierta de la cisterna, que intuimos estaría resuelta con planchas de madera o losas de piedra. El depósito, que se nutriría de aguas pluviales, se adentra en su extremo occidental hasta la zona del corredor (ámbito 6), donde se sitúa el pozo de extracción del agua.

A tenor de la escasez de registro estratigráfico conservado en todo este sector del asentamiento, la excavación de la cisterna, por su naturaleza, abrió amplias expectativas. En su interior se identificaron dos fases de relleno: la superior, correspondiente al nivel de colmatación intencionada del depósito y, debajo de esta, la que identificamos como de uso de la cisterna. Los estratos superiores del relleno, con una potencia media entre 1,20 y 1,50 m, corresponden al momento de inutilización de la instalación. Están formados por arcilla procedente de los alzados de tapial y adobe de los muros de las estancias inmediatas. Algunas porciones de estos muros conservaban aún los adobes en disposición articulada, lo que indica que fueron derribados intencionadamente hacia el interior de la cisterna, contribuyendo a su colmatación; todo ello aparece asociado a una gran cantidad de material constructivo de revestimiento: parietal (molduras, estucos pintados), fragmentos de techo y de pavimentos. El estrato inferior de la cisterna era de poca potencia, entre 10 y $45 \mathrm{~cm}$, y estaba formado por limos de origen sedimentario. En este nivel, la presencia de material cerámico relativamente entero indica que su formación tuvo lugar cuando la estructura hidráulica estaba en uso, antes de su abandono definitivo. La tipología de las piezas recuperadas parece confirmar esta interpretación, ya que algunas de ellas están relacionadas con la extracción de agua, como es el caso de una jarra con asa de cesta en cerámica ibérica pintada o un asa de bronce perteneciente a una situla. También se han recuperado restos de materia orgánica consistentes en pequeños fragmentos de cuerda de esparto trenzado.

Como habíamos indicado anteriormente el patio estaba rodeado, en sus alas norte y oeste, por una galería en forma de L. La lógica constructiva sugiere interpretar este espacio como un corredor porticado abierto al patio y que estructuralmente favorecería la circulación, iluminación y ventilación de las estancias dispuestas a su alrededor.

En el sector oriental se disponen cuatro habitaciones (ámbitos 5, 10, 11 y 21) todas ellas conservadas a nivel de cimentación y sin vestigios de su pavimentación original, ni de los accesos y conexión entre ellas.

Si continuamos hacia el sur encontramos un nuevo conjunto de estancias. En primer lugar el ámbito 7, que limita con el patio; esta es una de las habitaciones más grandes del complejo $\left(52 \mathrm{~m}^{2}\right)$, y sus muros están conservados a nivel de cimentación. El hallazgo de teselas blancas y restos de cerámica triturada en su superficie nos hace suponer que originalmente la estancia estaría pavimentada con un opus signinum teselado. Adosadas al muro sur se sitúa un conjunto 
de cuatro habitaciones, tres de ellas (ámbitos 9, 14 y 15) con el nivel de circulación ligeramente más bajo $(80 \mathrm{~cm}$ ) respecto las otras estancias del complejo (Fig. 7); esta diferencia de cota se debe a que su construcción se adaptó al desnivel natural que mostraba la vertiente del

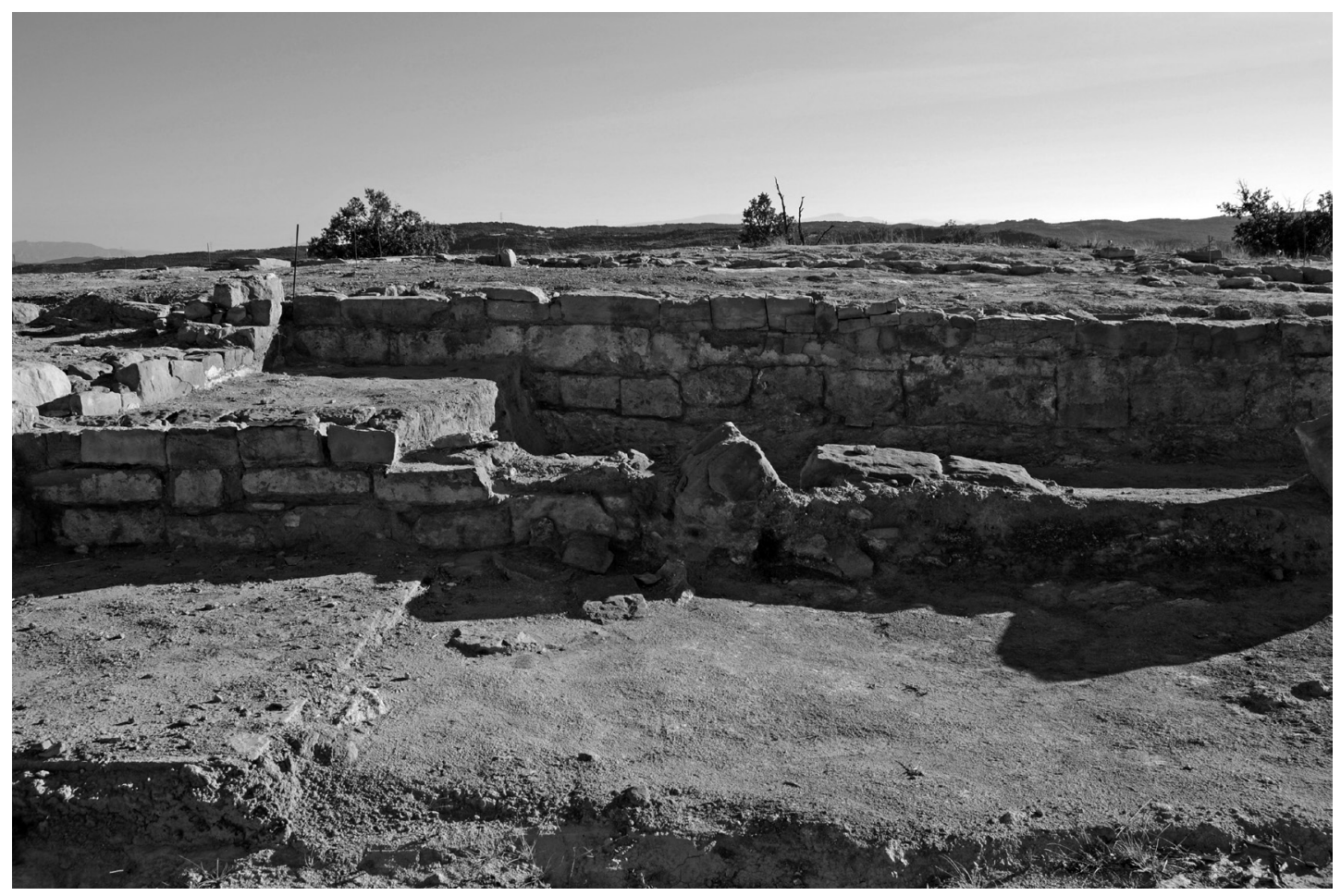

Figura 7. Estancias del lado sur del edificio principal, donde se puede apreciar la diferencia de cota entre terrazas. Asimismo, se puede observar la técnica constructiva empleada en los muros, con zócalos de piedra tallada (Fotografía Equipo UAB).

cerro, como se ha indicado. El ámbito 9 es una amplia habitación rectangular de unos $30 \mathrm{~m}^{2}$ y un pavimento de tierra batida que conserva en su centro una base cuadrada de piedra, que relacionamos con algún soporte vertical desaparecido. Gracias a su ubicación ligeramente más baja que el resto del edificio se ha preservado una parte de su estratigrafía, que muestra signos evidentes de destrucción por un incendio que comportó el colapso de la estancia; en su interior se suceden capas de ceniza, materia orgánica carbonizada, arcilla quemada y adobes en conexión procedentes de las paredes y techo. Todo parece indicar que en el momento del incendio el interior de la estancia se encontraba vacío; la escasez de materiales recuperados entre las capas de ceniza y restos de vigas carbonizadas así lo indica. Destaca el hallazgo de uno de los únicos ejemplares de militaria localizados in situ en el yacimiento: una punta de regatón de hierro correspondiente al asta de un arma larga. El incendio que destruyó el ámbito 9 afectó también a las habitaciones contiguas, los ámbitos 14 y 15, que cierran el complejo por el lado sur. Se trata de dos estancias estrechas y alargadas, de dimensiones bastante similares: $18 \mathrm{~m}^{2}$ y $19 \mathrm{~m}^{2}$, respectivamente, separadas por un pequeño muro. En estos dos ámbitos también se han excavado niveles de cenizas que cubrían el pavimento original de tierra batida, a excepción del extremo oriental del ámbito 14 que conserva visible un pequeño enlosado de buena factura $(2,25 \times 1,90 \mathrm{~m})$, construido con losas regulares, una de las cuales tapaba un pequeño 
receptáculo excavado bajo el pavimento que apareció vacío. Esta pavimentación creemos que obedece a la existencia de un espacio cerrado o recámara dentro de la misma habitación 14, a la que se accedería a través de una puerta de doble hoja, tal como indican dos rebajes para los quicios. En la misma ala sur encontramos el ámbito 8. Se trata de un pequeño espacio de $30 \mathrm{~m}^{2}$, cuyo nivel de uso ha desaparecido por completo por efecto de la erosión; en este caso el terreno natural no fue recortado como en los ámbitos vecinos. Cabe la posibilidad que en este espacio se encontrara uno de los accesos al complejo superior como sugieren los restos de posibles peldaños de escalera.

El ala oeste del edificio principal lo forman un total de cinco habitaciones dispuestas en batería, abiertas todas ellas al corredor porticado del patio. Estas estancias muestran dimensiones bastante similares que oscilan entre $\operatorname{los} 27 \mathrm{~m}^{2}$ y los $29 \mathrm{~m}^{2}$, con la excepción del ámbito 1 que no sobrepasaba los $16 \mathrm{~m}^{2}$, y el 12, de mayores dimensiones, que no se han podido determinar por la erosión que presenta. La característica excepcional de estas habitaciones es la tipología de sus pavimentos. Pudimos comprobar que originariamente estas estancias habían estado revestidas con elaborados suelos de terrazo de diversa composición y color (blanco, rojo, blanconegro-rojo y blanco-rojo), siendo el ámbito 4 donde hallamos el ejemplo mejor conservado in situ: un terrazo blanco, realizado con cal y piedra blanca pulida. Uno de los factores que han incidido en la mala conservación y pérdida de estos niveles de circulación es su construcción sin un rudus de preparación que cimentara su base, quedando la estructura muy debilitada, a merced de la acción de las raíces al estar en contacto directo con el propio terreno, lo que supone una deficiencia estructural evidente. Paradójicamente, y a pesar de este problema, los pavimentos mostraban signos de una gran calidad de ejecución. Los variados cromatismos junto a sus superficies pulidas debieron conferir un acabado lujoso a las diferentes estancias, aunque no estuvieran pensados para perdurar durante muchos años.

El cierre del edificio por la parte norte corresponde al ámbito 12; nos ha resultado difícil precisar sus límites al ser la zona más afectada por la erosión. Aun así, se ha podido seguir en parte su suelo original, uno de los más extensos de todo el complejo. Deducimos, por su composición, que debió ser uno de los más vistosos al combinar tres colores: cerámica triturada y dos tipos de piedra, blanca y negra, dando como resultado un terrazo bien resuelto cromáticamente (rojo-blanco-negro). Lamentablemente este pavimento fue desenterrado hace unas décadas por los aficionados locales por lo que actualmente se encuentra casi desintegrado.

El saqueo de piedras y sillares que claramente muestran algunos muros y cimientos del edificio principal nos lleva a la conclusión que en el momento del abandono se llevó a cabo un desmontaje sistemático de aquellos elementos constructivos que aún poseían un cierto valor para la construcción, especialmente tejas y sillares. Estos materiales se debieron reutilizar en otros enclaves próximos, que bien pudieran ser la ciudad romana de Iesso (Guissona), situada a 6 km, o la villa de Sant Pelegrí (Biosca), situada tan solo a $300 \mathrm{~m}$ al pie del cerro; sin descartar totalmente la posibilidad que una parte de este expolio de material constructivo se hubiera realizado en algún otro momento histórico difícil de precisar y que no ha dejado evidencias.

\section{EL EDIFICIO PRINCIPAL. TÉCNICAS CONSTRUCTIVAS}

En el capítulo anterior ya nos hemos referido a algunas de las técnicas utilizadas en la construcción del edificio principal, pero conviene profundizar en algunos detalles. A partir de los restos encontrados todo parece indicar que los muros fueron alzados con tapial y/o adobe, dispuesto sobre un zócalo construido con piedra tallada (Fig. 7). Hemos podido comprobar que, como mínimo, una hilada de sillares se levantaría sobre los cimientos de piedra. Los ci- 
mientos de estos muros suelen tener una o dos hiladas en función de los desniveles naturales y de la carga que debieran soportar, y fueron construidos utilizando piedras tendentes a la regularidad, sin mortero. El tipo de piedra arenisca empleada en los cimientos y en los zócalos es de la misma naturaleza que la que se utilizó para la construcción de la muralla. Cabe destacar el esfuerzo que supuso la obtención y transporte de este tipo de piedra desde alguna cantera cercana no determinada, ya que no es originaria del cerro. El uso del barro en la construcción es muy habitual en todas las épocas, al ser un material abundante, económico y que permite una rápida ejecución, además de dotar de una gran confortabilidad térmica a los habitáculos; permite a su vez aplicar acabados sobre sus superficies vistas, como los estucos decorativos anteriormente mencionados.

Tal y como hemos referido, el edificio muestra diversidad de pavimentos en las estancias (Fig. 8). Los artesanos emplearon diferentes combinaciones de materiales (pétreos y cerámicos) para conseguir efectos cromáticos en los mismos. Los análisis arqueométricos realizados sobre algunas muestras (Rodà et alii, 2013a; 2013b) han permitido caracterizar los materiales

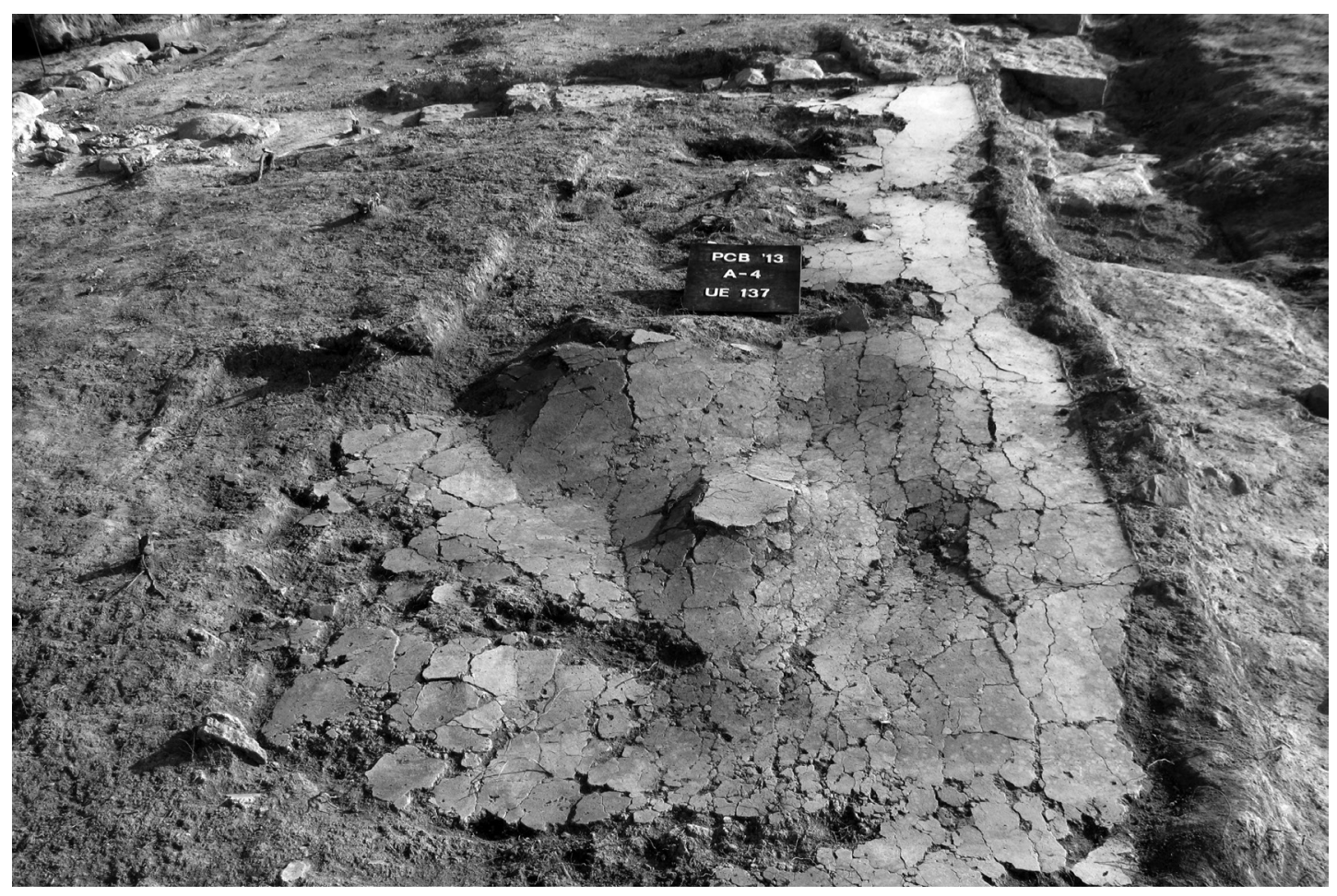

Figura 8. Detalle del pavimento de terrazo del ámbito 4, elaborado con piedra blanca (Fotografía Equipo UAB).

empleados en su construcción: la piedra blanca corresponde a calizas micríticas con foraminíferos; la piedra negra es una metapelita con andalucita, y para la tonalidad rojiza se emplearon simples fragmentos de cerámica de cocción oxidante. Así pues, los artesanos que construyeron estos pavimentos conocían perfectamente la técnica constructiva y realizaron una cuidadosa elección de los materiales a emplear. A tenor de la cronología estimada podemos presentar el conjunto de Puig Castellar de Biosca como uno de los primeros yacimientos conocidos en el empleo de estas técnicas constructivas en Hispania. 
Las estancias secundarias del complejo, así como los espacios a cielo abierto, disponen de simples suelos realizados con tierra compactada. Hemos podido documentar estos niveles de circulación en los ámbitos 3 y 6 , que corresponden a la zona de patio y el corredor del edificio, respectivamente, así como en los ámbitos 9,14 y 15.

En cuanto a los revestimientos parietales, no tenemos ninguna duda que los interiores de las estancias nobles irían revestidos con estucos o enlucidos pintados. Hemos recuperado numerosas muestras de ellos de color blanco y, más ocasionalmente, rojo y ocre en los niveles de derrumbe que rellenaban la cisterna, y también en muchos de los estratos superficiales del yacimiento. Los análisis arqueométricos a que hemos sometido algunos enlucidos nos indican una técnica de ejecución muy elaborada, con varias capas de preparación (en algunos de los casos analizados, se detectan hasta tres capas) y una cuidada elección de los materiales empleados, entre los que destaca la presencia de caliza blanca pulverizada del mismo tipo (micrítica fosilífera) que la empleada en los pavimentos analizados. En algunos casos, estos revestimientos también debieron recubrir el techo de alguna estancia, tal como sugieren las improntas de cañizo en la parte posterior de algunos de ellos. Algunos fragmentos recuperados muestran relieves biselados y moldurados, que se podrían asimilar a una decoración de primer estilo pompeyano, un estilo decorativo propio del siglo II a. C. Cabe destacar también el uso de un tipo de estuco parietal muy sofisticado, obtenido con mortero de cal y cerámica pulverizada, componente que da al estuco una coloración rosada, y que en ningún caso se puede confundir con un opus signinum tradicional. Las cubiertas de las estancias nobles creemos que serían de tegulae, a pesar de los escasos fragmentos recuperados hasta ahora en el asentamiento, solo tres, un número irrisorio a tenor de la cantidad en que habitualmente aparece este material constructivo. Esta ausencia nos llama enormemente la atención y a nuestro parecer es indicativo de una probable recuperación de este material constructivo en el momento del desmantelamiento del complejo. A esta observación hay que sumar el análisis arqueométrico practicado sobre dos de los fragmentos de teja recuperados que ha servido para precisar su procedencia itálica (Campania y Lacio). Este dato nos parece remarcable en un establecimiento de esta cronología, aunque no es un unicum, puesto que esta procedencia itálica coincide con otros lotes de tejas analizados por nuestro equipo en los yacimientos contemporáneos de $\mathrm{Ca}$ l'Arnau (Cabrera de Mar) y Can Tacó (Montornès-Montmeló).

\section{LA MURALLA. DESCRIPCIÓN}

Los primeros trabajos de excavación realizados en la zona de la muralla perimetral que recorre el cerro de Puig Castellar (Figs. 2 y 3 ) se centraron en la extracción de la capa superficial de origen vegetal que cubría esta estructura, con el objetivo de dejar al descubierto su trazado. Podemos confirmar que se trata de una muralla defensiva provista de torres y baluartes. Por ahora solo ha sido posible excavar una de las torres; se trata de una estructura de planta cuadrada plenamente integrada en la muralla y proyectada hacia el exterior, con un relleno interno de piedras y tierra que le confiere solidez, y una superficie de $18 \mathrm{~m}^{2}$. El resto de torres todavía no han sido excavadas, más allá de documentar su existencia, pero todo parece indicar que seguirán el mismo modelo tipológico.

El lienzo de muralla que cierra la fortificación por la vertiente sur es el mejor conservado, se conoce en una extensión de más de 250 metros (Fig. 9). Su trazado no es totalmente rectilíneo siendo a partir de la torre que hemos descrito que adopta una ligera inflexión de pocos grados en su orientación a fin de adaptarse mejor a la topografía del terreno. En el extremo sudeste, la muralla forma un ángulo de unos $100^{\circ}$ en dirección norte para cerrar la fortificación 


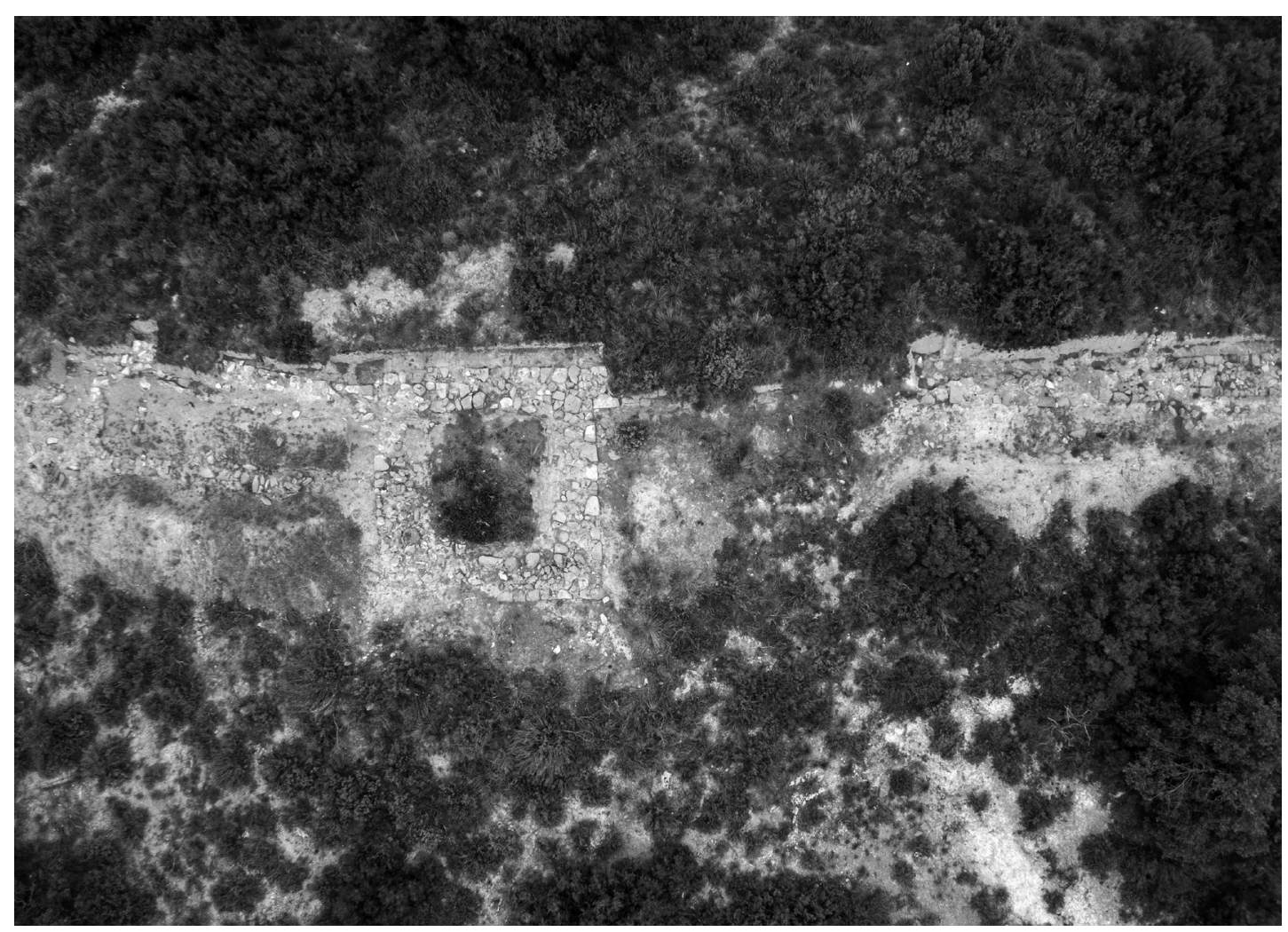

Figura 9. Vista aérea de parte del lienzo sur de la muralla, con una de sus torres (Foto Equipo UAB).

por el este; en este punto se han excavado dos sólidas estructuras $(\mathrm{C} 1$ y $\mathrm{C} 2)$ adosadas a la cara interna de la muralla, unos ámbitos que, por las dimensiones de sus muros, de casi $1 \mathrm{~m}$ de espesor, nos hacen pensar que podrían haber soportado un piso superior y por este motivo podrían haber tenido la función de baluarte defensivo. Este lienzo de muralla, a pesar de mostrar algunos tramos perdidos por efecto de la erosión, tiene un trazado totalmente recto y es donde se encontraba el acceso principal al recinto. En este paramento tenemos indicios claros de la existencia de una puerta, y así lo sugiere también la topografía del cerro en esta zona que se corresponde con el actual camino de acceso. La muralla del sector oeste no ha sido aún objeto de intervención arqueológica pero la existencia de diversas alineaciones de piedras en superficie nos marca perfectamente su trazado por este sector. El paramento que cerraría el recinto por el norte, que cabe recordar como la zona donde las vertientes son más pronunciadas, resulta más difícil de reconocer, al tratarse de una zona muy abrupta y erosionada por los barrancos de escorrentía natural, aunque se puede determinar su orientación a partir de la presencia de algunos bloques perfectamente alineados.

La muralla no dispone de foso exterior puesto que no es necesaria su existencia al estar construida en las laderas de un cerro con un desnivel natural muy pronunciado.

La organización del espacio interno de la fortificación, al margen del edificio principal ya descrito, empieza a ser conocido. Todos los indicios apuntan a que habría amplias zonas sin edificar, u ocupadas con construcciones que no han dejado rastro visible. Recientes campañas de excavación han permitido constatar la existencia de diversas habitaciones (14 a día de hoy) dispuestas en batería y adosadas directamente al lienzo interno de la muralla meridional (Fig. 10). Aunque por el momento no es posible precisar las funciones y usos a que se destinaron 


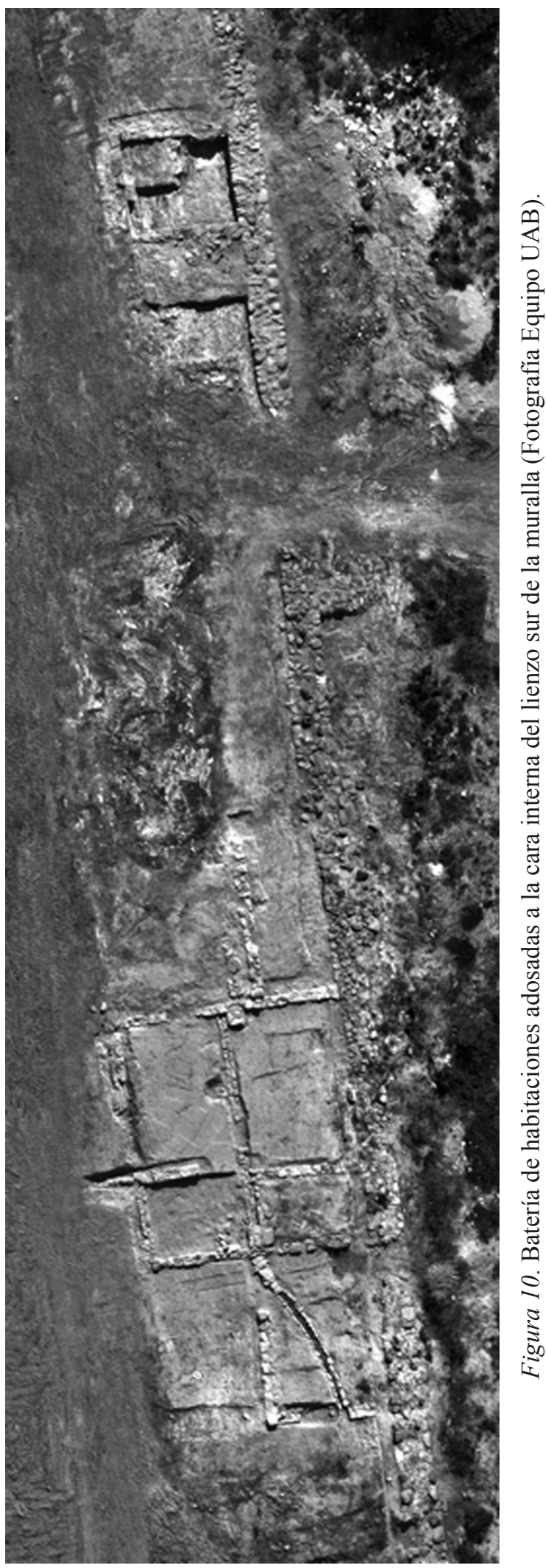

Gladius, XXXIX (2019), pp. 19-43. ISSN: 0436-029X. https://doi.org/10.3989/gladius.2019.02 
estos espacios, al estar en proceso de excavación, partimos de la hipótesis de que lo más probable es que tuvieran un uso residencial para la tropa del destacamento militar. La existencia de estas estructuras habitacionales reforzaría la propia muralla, aunque a su vez imposibilita la existencia de un intervallum.

\section{LA MURALLA. TÉCNICAS CONSTRUCTIVAS}

La tipología de la muralla viene conformada por una base de bloques de piedra que se disponen directamente sobre la roca natural recortada, sin indicios claros de otro tipo de cimentación. Presenta una anchura en la base que oscila entre 1 y 1,20 m y una altura conservada de $80 \mathrm{~cm}$. La piedra utilizada en su construcción es arenisca, igual que la empleada en el resto de construcciones del asentamiento; en menor proporción encontramos bloques de yeso cristalizado, procedentes del mismo cerro, que se dispusieron aleatoriamente, sobre todo en el relleno interno de la estructura. Los bloques de arenisca son de distintos tamaños, pero con tendencia a la regularidad, especialmente los que forman las hiladas inferiores, seleccionados para dar más estabilidad al paramento. Los bloques se disponen formando pseudo-hiladas, de las que se han conservado entre dos y tres, aunque pensamos que originariamente habría otras tantas. Las piedras visibles de la cortina interior y exterior del muro están careadas, mientras que en las del relleno interior (emplecton) son de formas irregulares. En la construcción de la muralla se utilizó una argamasa muy simple mezclando tierra y yeso, un material abundante en el entorno inmediato. Tomando como referencia otras murallas de este período, consideramos que la base de la muralla construida en piedra no sobrepasaría en origen 1,5 m de altura, siendo el resto del alzado construido con tapial, alcanzando una altura total estimada no inferior a 5 m (Morillo y Adroher, 2014; Morillo, 2016). Quizás esto ayude a explicar el escaso número de bloques de piedra caídos en el frontal de la muralla. Esta técnica no impide que en los puntos donde la muralla lo requiriese la base de piedra podría haber tenido una altura superior, tal y como parece perfilarse en los ángulos y en los paramentos de la torre conocida.

\section{ANÁLISIS DE LOS MATERIALES}

Las excavaciones han proporcionado un importante conjunto cerámico que marca un horizonte cronológico propio del segundo y tercer cuarto del siglo II a. C., unos materiales que, por su variedad, resultan muy representativos de este momento de contacto entre el mundo romano y el mundo indígena. En el conjunto de materiales recuperados encontramos ampliamente representadas las ánforas y las cerámicas de tradición ibérica conviviendo con un extenso repertorio cerámico de origen foráneo, sobre todo itálico, por lo cual no es de extrañar que el yacimiento se considerara inicialmente como un establecimiento ibérico.

El conjunto cerámico recuperado en Puig Castellar se ha cuantificado en número mínimo de individuos (NMI). A partir de los inventarios de material recuperado entre los años 2011 y 2017 podemos observar una importante presencia de ánforas de importación (43 ind.) con predominio de las de origen itálico; también entre la vajilla de mesa (233 ind.) (Fig. 11) resulta significativa la presencia del barniz negro de origen itálico (175 ind.), unas proporciones que a priori podrían sorprender en un yacimiento que dista $100 \mathrm{~km}$ de la costa y teniendo en cuenta las dificultades del transporte terrestre por la precariedad de las vías de comunicación del momento. 


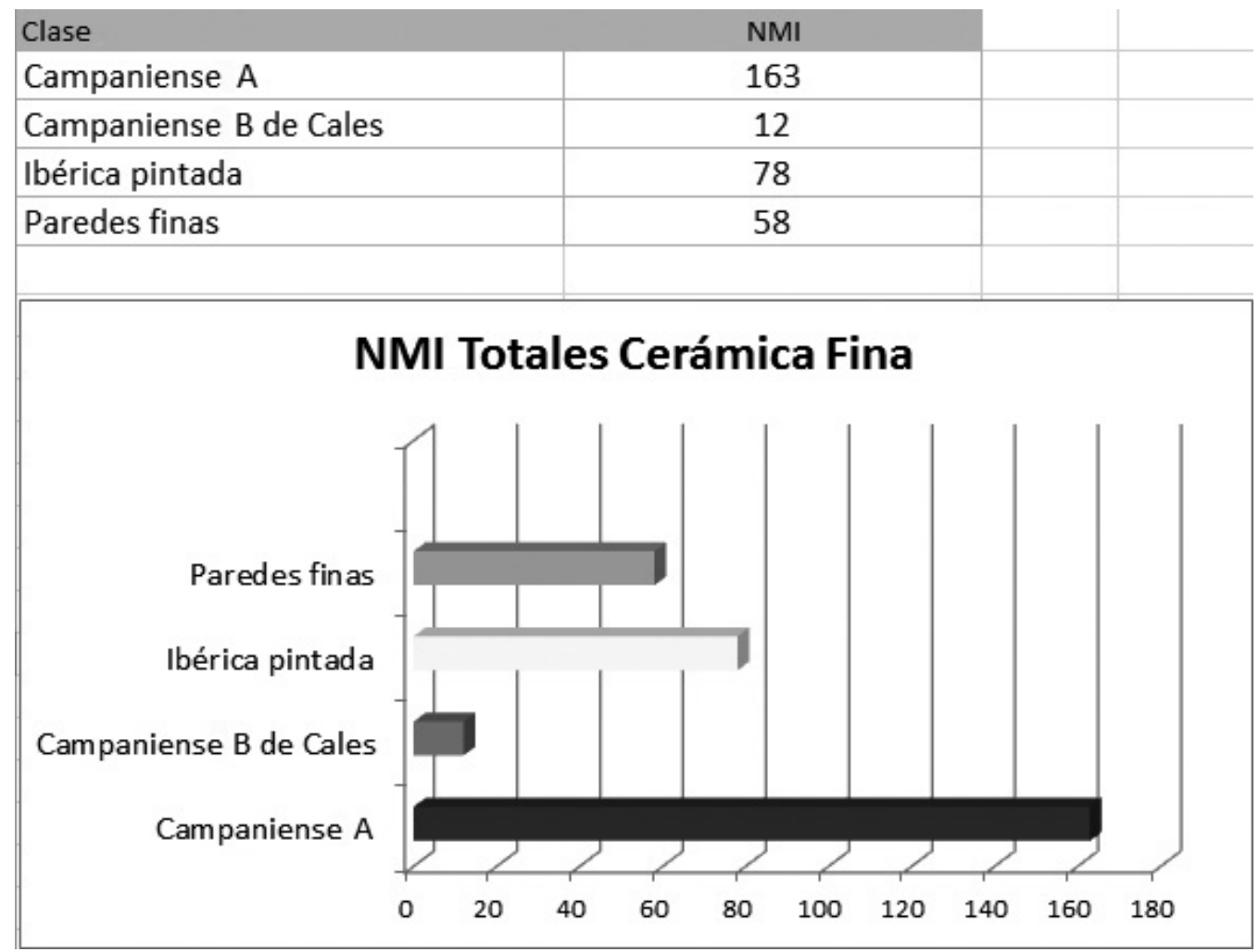

Figura 11. Gráfico de los distintos tipos de cerámica fina recuperada entre 2011 y 2017 en Puig Castellar (Autor: César Carreras).

Analizando el conjunto de cerámicas finas de importación (Fig. 12) destacamos la presencia casi absoluta de cerámica campaniense de tipo A (163 ind.), formas Lamboglia 5, 6, 23, 27ab, 27 b, 27c, 28, 31b, 33b, 36, F3130, F2544 y F8150; aunque hay un predominio de formas de la variedad media, queremos destacar la presencia significativa de algunas formas antiguas del repertorio de la campaniense A como son el plato Lamboglia 23 (14 ind.), fragmentos de diferentes gutti F8150 y de copas F3130. También merecen mención 2 copitas del Taller de Roses, forma $10 \mathrm{~A}$. La presencia de estas formas antiguas nos lleva a precisar una cronología inicial para el establecimiento en torno al $180 \mathrm{a}$. C. Asimismo cabe destacar la poca representación de campaniense de tipo B (12 individuos) con formas de producción calena media Lamboglia 3, 8 y Morel 4753, vasos que podemos atribuir al último tercio del siglo II a. C. Finalmente, el grupo de cerámicas finas se completaría con una representación de vasos de paredes finas (58 individuos) de las formas Mayet I, II y III. Si integramos en esta relación la cerámica pintada de tipo ibérico como vajilla fina, este tipo está bien representado (78 individuos), la mayoría de ellos kalathoi.

Por lo que se refiere a la cerámica común (Fig. 13), hay un predominio de las producciones oxidantes tanto romanas como de tradición ibérica, así como algunas ollas de cerámica reductora de cocina, estas últimas muy poco representadas. Habría que destacar también la presencia de cerámica ibérica gris de la costa (14 ind.) y algunas importaciones de cazuelas y morteros de origen itálico (forma Emporiae 36.2, COM-ITA 8b y 8c), junto a una mínima representación de cazuelas púnicas (3 ind.). 


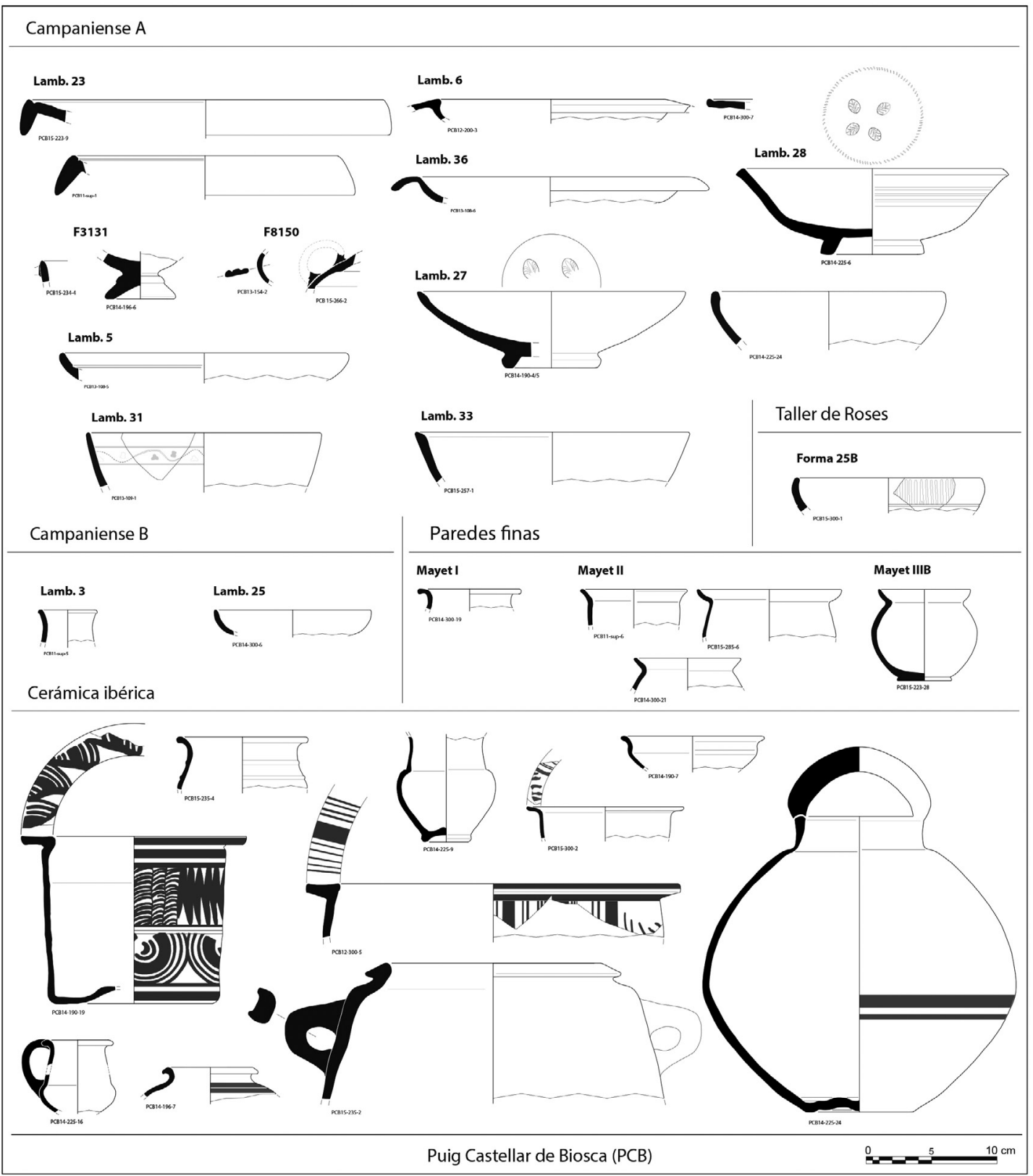

Figura 12. Contexto material de Puig Castellar de Biosca. Cerámica fina (Autor: Equipo UAB).

Las ánforas (Fig. 13) constituyen un buen ejemplo para conocer los abastecimientos del enclave, sobre todo representadas por los envases vinarios. Las formas de ánfora documentadas son las habituales de este período: las greco-itálicas (clásicas y de transición) y las Dressel 1A, que marcan una horquilla cronológica entre 175 y 120 a. C. El dato que nos parece más relevante de este material es la gran variedad de pastas cerámicas que muestran las ánforas recuperadas, indicativo de una amplia diversidad de procedencias. El análisis macroscópico de las pastas se ha comparado con algunos repertorios arqueométricos disponibles (proyectos FACEM e IMMENSA AEQUORA), reconociendo ánforas procedentes de Palermo, Calabria, 


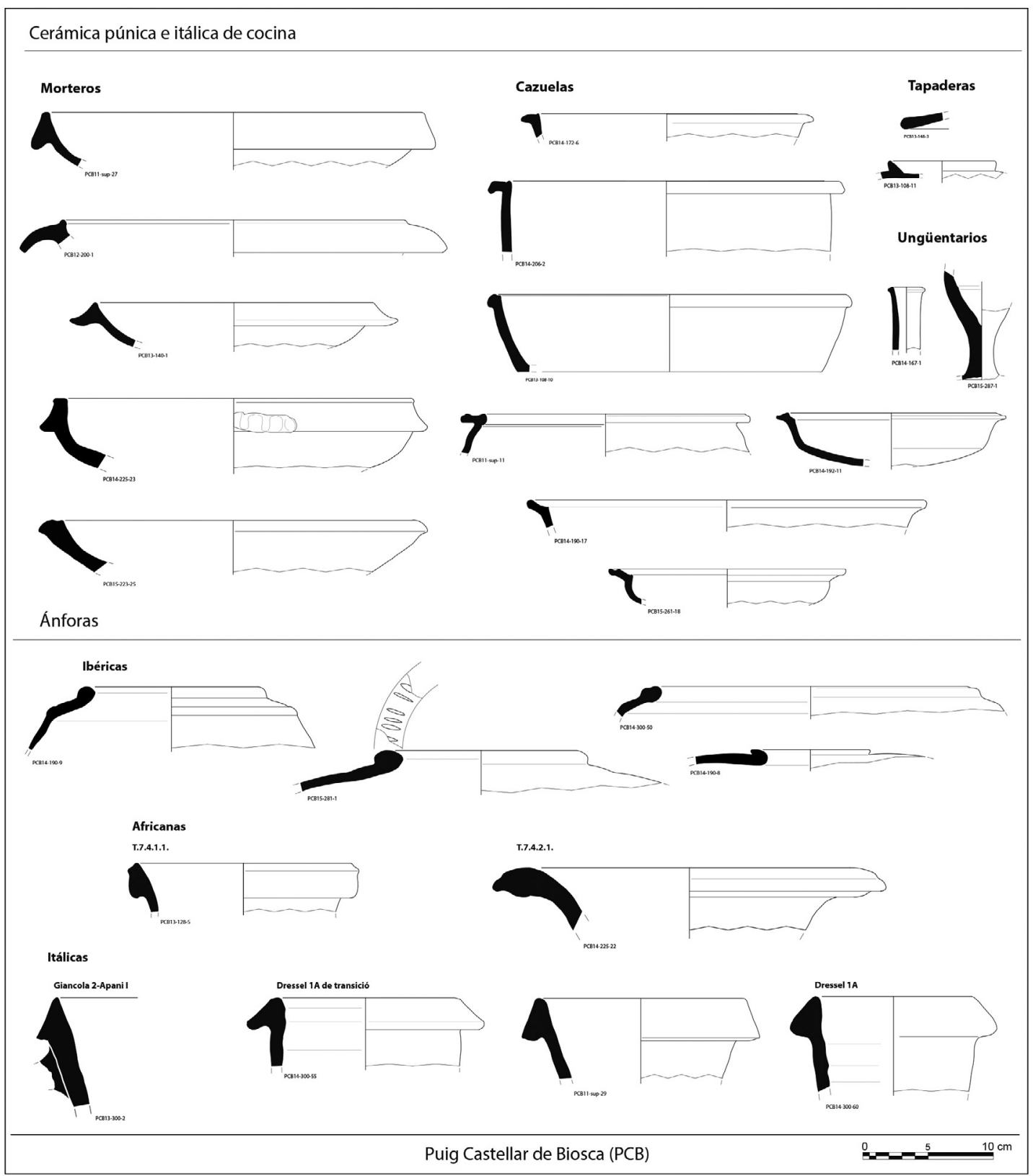

Figura 13. Contexto material de Puig Castellar de Biosca. Cerámica común y de cocina importada y ánforas (Autor: Equipo UAB).

Lucania, sur de la bahía de Nápoles, Etruria, Lacio y, sobre todo, la producción vesubiana (Olcese, 2012). De procedencia adriática cabe destacar cuatro ejemplares de ánfora brindisina (Giancola 2/Apani I) (Carreras et alii, 2016) y una Dressel 1A picena con chamota. De origen peninsular se han identificado pastas de procedencia ebusitana y de la bahía de Cádiz, así como un número muy elevado de ánforas ibéricas (116 ind.). El último grupo identificado son las ánforas de procedencia africana, dos formas T.7.4.1.1 y dos T.7.4.2.1, una producción que 
tendría su momento álgido a mediados de siglo II a. C. (Ramon, 1995), perdurando hasta el tercer cuarto del siglo.

El extenso repertorio de pastas anfóricas que acabamos de describir también se constata en otros yacimientos del noreste peninsular como Can Tacó (Montmeló), Ca l'Arnau (Cabrera de Mar), Sant Miquel de Sorba, Bolvir, Empúries y Tarraco. Esta comprobación se ha llevado a cabo directamente por nuestro equipo en los yacimientos enumerados anteriormente. La presencia de estos materiales importados es un dato que nos parece significativo destacar puesto que, a partir del último cuarto de siglo II a. C., se evidencia un cambio de tendencia que lleva a uniformizar la procedencia de estos suministros anfóricos.

A la vista del material documentado todo parece indicar que alrededor del 120 a. C. se abandonaría el yacimiento de Puig Castellar. Al respecto cabe recordar que las fosas fundacionales de la vecina ciudad romana de Iesso (Guissona), fechadas hacia el 120 a. C. por una marca consular del 121 a. C. (Guitart et alii, 1998; Cormack et alii, 2007), proporcionan también un amplio conjunto de ánforas en el que la forma Dressel $1 \mathrm{~A}$ es la predominante, junto a variedades ya más modernas como la Dressel $1 \mathrm{C}$ y la Giancola 5/Apani V, y con una variedad de pastas mucho menor; el conjunto anfórico de Iesso pues, marca un horizonte ligeramente más moderno que el que presenta Puig Castellar de Biosca.

El amplio catálogo anfórico recuperado es indicativo de un abastecimiento diverso y continuado de vinos itálicos, así como de otros productos africanos y peninsulares; esta gran diversidad de orígenes nos parece indicativa de la existencia de un sistema de suministros bien estructurado y regular como el que abastecía al ejército romano en este periodo.

Las excavaciones han proporcionado hasta ahora muy poco material metálico, en parte debido la intensa actividad clandestina a la que ha sido sometido el yacimiento durante décadas. Se conocen tan solo dos monedas en colecciones particulares que con seguridad podemos atribuir a Puig Castellar: un cuadrante de Kesse ( $1^{\text {a }} \operatorname{mitad}$ s. II a. C.) y otro de Arse (último cuarto s. II a. C.). Otros objetos metálicos recuperados en excavación son un asa de bronce de situla, procedente de la cisterna, tres pequeños pernos de bronce y diversas gotas de plomo fundido. Entre los materiales de carácter estrictamente militar, se encontró una punta de flecha de bronce con nervio central y un regatón en hierro de asta de un arma larga. A pesar de esta escasez de objetos metálicos, es importante destacar que en el interior del recinto amurallado se ha identificado una zona marginal dedicada a la actividad metalúrgica; este sector muestra una gran concentración de escoria de hierro, con más de 200 restos de escoria procedentes del crisol documentados hasta ahora, unos subproductos resultantes del proceso metalúrgico basado en la reducción de mineral férrico para la obtención de hierro. Esta zona está actualmente en curso de excavación y no se puede precisar aún la envergadura total de esta industria, aunque presumimos fue importante y muy acorde para ser llevada a cabo en un establecimiento militar de estas características; de confirmarse este aspecto, sería uno de los primeros ejemplos documentados en Hispania de actividad metalúrgica primaria llevada a cabo por el ejército romano.

\section{CONCLUSIONES}

Hasta donde hoy conocemos, podemos considerar Puig Castellar de Biosca como un yacimiento singular en su tipología de castellum, al ser un establecimiento militar con una estructura sin paralelos directos conocidos, pero con una importante significación histórica para el conocimiento de la primera presencia romana en la península (Fig. 14). El carácter militar romano que proponemos para el establecimiento, a pesar de no disponer de restos significativos de militaria, se basa en diferentes evidencias: en primer lugar su cronología muy precisa 


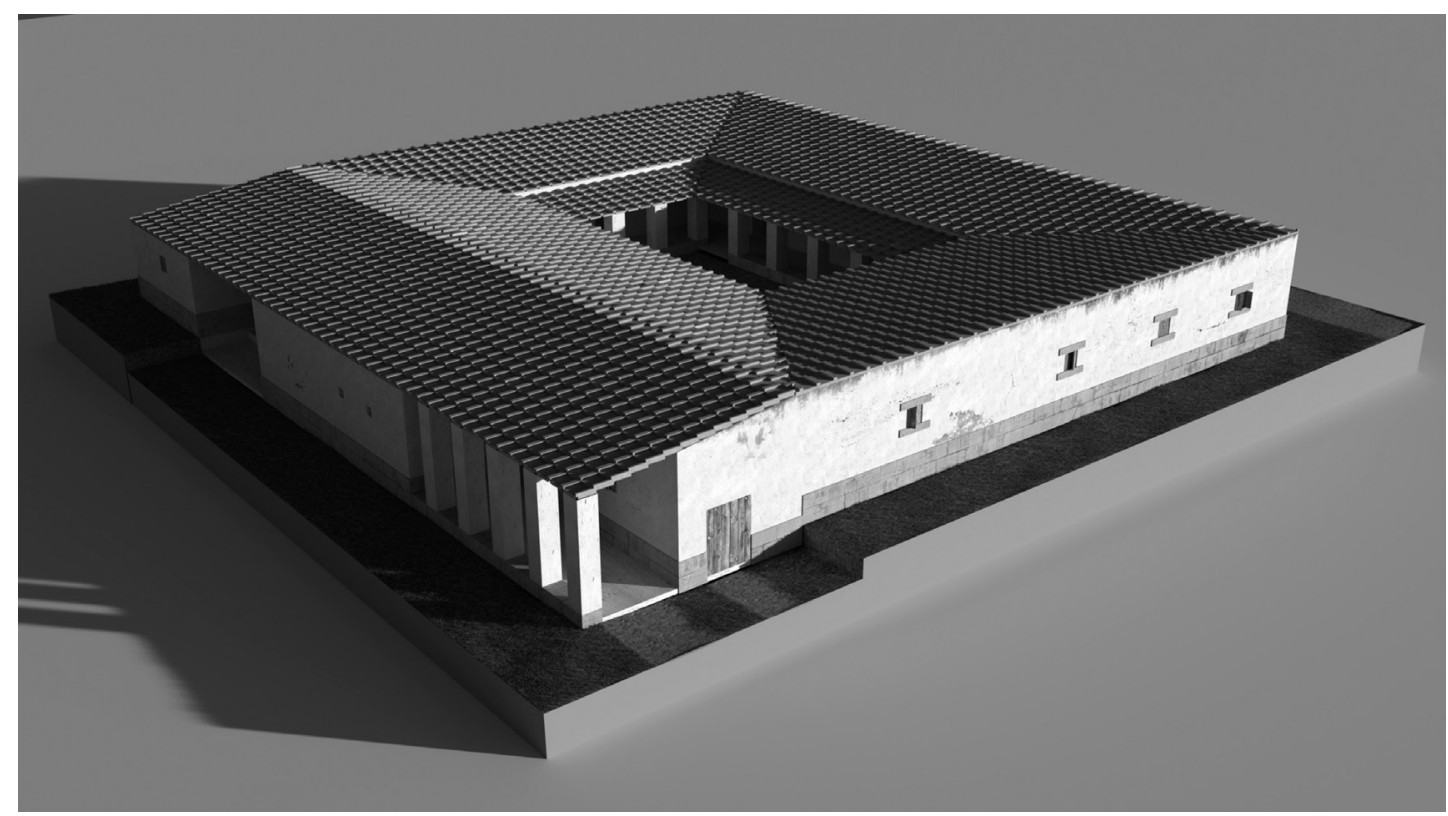

Figura 14. Propuesta de restitución 3D del edificio principal de Puig Castellar (Autor: Mario Aguilar).

(180-120 a. C.); también resulta significativa la ubicación en altura con amplio dominio visual del entorno y su considerable extensión (1,5 ha); la tipología singular, única hasta ahora, de su edificio más emblemático; la existencia de una muralla defensiva de matriz romana, con paralelos en otras zonas peninsulares, construida con piedra procedente de canteras alejadas del yacimiento; la utilización temprana en Hispania de una serie de técnicas constructivas propias de la arquitectura suntuaria de tipo itálico, tales como pavimentos de terrazo y opus signinum, tejas de procedencia itálica, estucos pintados y moldurados; e, igualmente significativa, la gran cantidad de materiales cerámicos de importación propios de campamentos con cronologías similares (Empúries, Tarraco y Numancia), unos materiales cuya presencia masiva solo pueden tener justificación si pertenecen a la red de suministros oficiales del ejército. Pensamos que la suma de todos estos elementos es suficiente para sustentar nuestra interpretación en torno a la naturaleza romana del asentamiento, y más aún si consideramos que la presencia ibérica en la comarca donde se ubica resulta prácticamente inexistente, o por lo menos, hasta el momento, no ha sido identificada.

Observando la distribución de los ámbitos que configuran la planta arquitectónica del edificio principal que preside el asentamiento (Fig. 14), vemos que se aproxima a los patrones de construcción propios de un centro de mando (praetorium-principia), una tipología de edificio que se documenta en muchos establecimientos militares, aunque la mayoría de los ejemplos conocidos hasta ahora pertenecen al período imperial. La existencia de habitaciones pavimentadas y decoradas con técnicas constructivas que siguen modelos itálicos resulta un elemento excepcional para esta época en Hispania y, por tanto, sitúa a Puig Castellar de Biosca como uno de los complejos de tipo itálico más antiguos documentados hasta ahora en la península ibérica. La muralla de tipo defensivo con una tipología que se ajusta a los patrones de fortificación militar conocidos para el periodo republicano (Morillo, 2016), constituye otro argumento a considerar en esta línea interpretativa y, asimismo, la extensión del perímetro amurallado de 1,5 ha supone una superficie adecuada para cobijar una guarnición militar con todos los servicios necesarios. 
En este momento empezamos a tener ejemplos de establecimientos romanos contemporáneos al de Puig Castellar en territorio hispánico, siendo la mayoría de tipo militar (Fig. 15). Precisamente, es en la zona de Cataluña donde hallamos una serie de yacimientos excavados recientemente como Can Tacó (Montornès-Montmeló) (Rodrigo et alii, 2013; 2014), Monteró (Camarasa) (Principal et alii, 2015), Sant Miquel de Sorba (Navès) (Asensio et alii, 2014), Puig Pelat (Alt Camp) (Díaz y Ramírez, 2015), Ca l'Arnau (Cabrera de Mar), Sant Julià de Ramis y Mas Gusó (Empordà) (Casas et alii, 2015), que muestran más similitudes en algunos

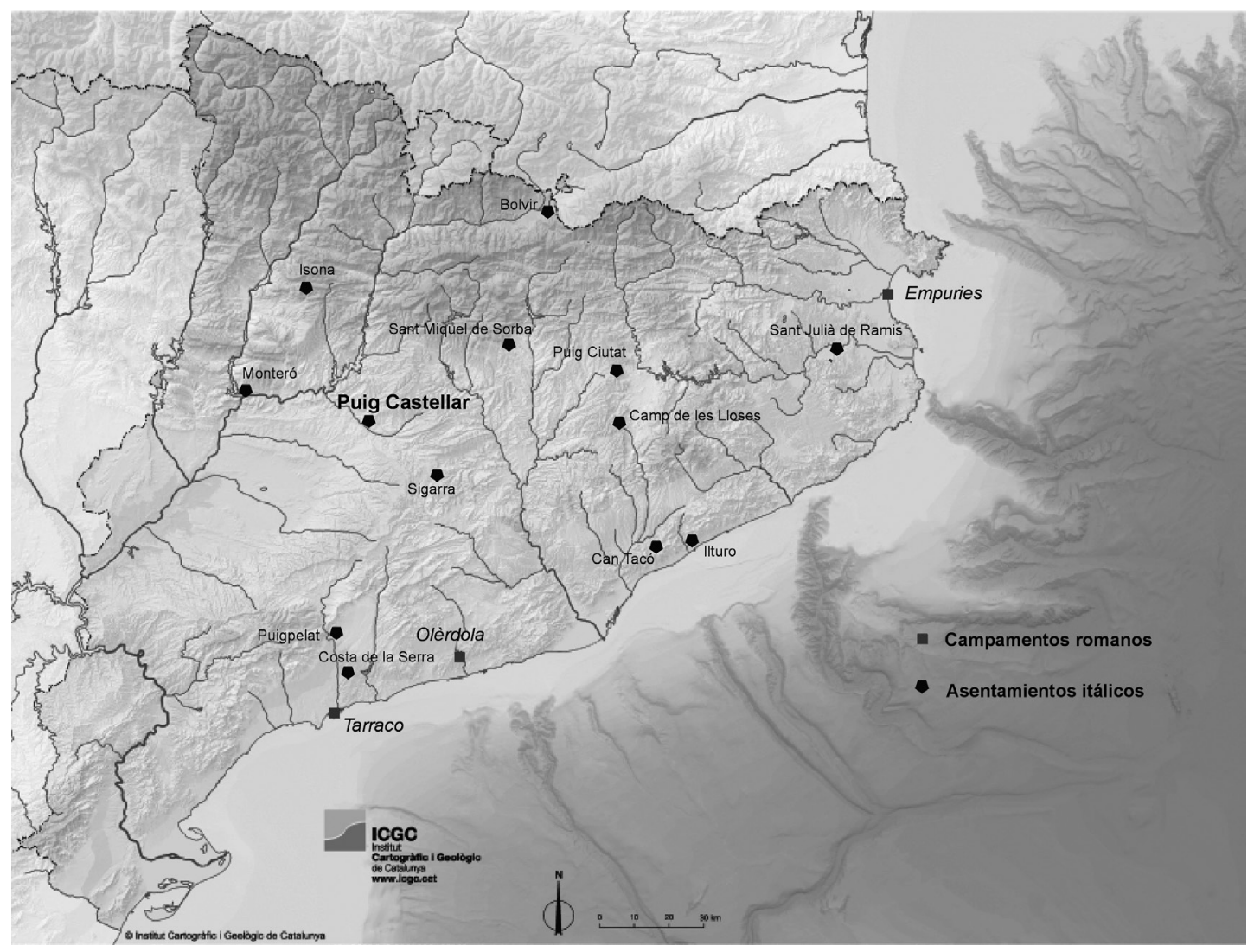

Figura 15. El nordeste hispánico en los siglos II-I a.C. Campamentos y establecimientos militares itálicos (Autor: César Carreras).

de sus aspectos cronológicos, tipológicos y/o funcionales con el yacimiento que nos ocupa; en este sentido, el conjunto de Puig Castellar de Biosca se ajusta perfectamente a una instalación romana de tipo militar, una adscripción que vendría reforzada por una cronología bien definida entre el 180 y el 120 a. C. Además de los anteriormente citados, otros yacimientos importantes del nordeste que muestran alguna de sus fases dentro de este período histórico son Olèrdola (Molist 2008), Sigarra (Els Prats de Rei), Serrat dels Espinyers-Aeso (Isona), El Camp de les Lloses (Tona), Puig Ciutat (Oristà), Tarraco y Empúries, así como otros de menor entidad. Aunque resulta prematuro establecer para todos ellos su función concreta, al estar la mayoría en curso de excavación, por los datos que nos han avanzado sus excavadores, los resultados finales van a incidir decisivamente en el conocimiento del primer siglo de la presencia romana en la zona del nordeste peninsular. 
Asimismo, conviene fijarnos en otros aspectos de Puig Castellar de Biosca que nos pueden ayudar a definir mejor el asentamiento y, sobre todo, su significación histórica en el marco de la primera implantación romana en Hispania. Un aspecto fundamental a considerar se refiere a la función que debió desempeñar el establecimiento, estudiado dentro del marco histórico y territorial del nordeste hispano. Cabe recordar que contemporáneamente a la ocupación de Puig Castellar de Biosca, Roma se encontraba involucrada en varios conflictos bélicos en Hispania, como las guerras en la Lusitania y en la Celtiberia, entre las que destacamos la larga campaña de Numancia (154-133 a. C.). En este escenario histórico se puede argumentar que Puig Castellar actuó como un castellum desde el cual se ejerció el control militar de una de las rutas que enlazaban la costa (Empúries o costa central) con el interior del país. Circulando por el valle del río Llobregós se llega hasta el río Segre y desde este se accede al valle del Ebro, siendo esta una de las rutas más importantes de acceso a la Meseta. Argumentos no faltan para defender esta hipótesis, pues esta vía atravesaba un territorio ya pacificado que ofrecía la seguridad necesaria desde la retaguardia para el trasiego de tropas en ruta, asegurando a su vez el tránsito de los suministros necesarios para proveer a los ejércitos en campaña del frente numantino. Siguiendo este planteamiento, la fortificación de Puig Castellar pudo tener una función de control para el territorio inmediato, pero sobre todo daría apoyo logístico, en caso necesario, a las tropas que circulaban por esta ruta. Su posición en altura, sus defensas, su considerable extensión y el fácil acceso desde el valle se ajustan perfectamente a esta finalidad (Pera et alii, 2016)

A pesar de la indiscutible posición estratégica del establecimiento y su control sobre el territorio inmediato, cabe considerar otras posibilidades interpretativas referidas a su función, sin descartar la que acabamos de exponer. No podemos dejar de comentar otros aspectos que hacen de Puig Castellar un yacimiento singular; nos referimos, en primer lugar, a las características que muestra el edificio principal del complejo (praetorium-principia), con la presencia de elementos arquitectónicos que podemos calificar de lujosos (tejas, estucados, molduras y pavimentos), todos ellos excepcionales para esta época en Hispania; en segundo lugar, destacamos la gran cantidad y diversidad de materiales de importación recuperados. Los dos aspectos aportan evidencias arqueológicas suficientemente significativas que nos ponen sobre la pista de que, al menos una parte de sus residentes disfrutaban de un estatus social privilegiado, con la voluntad manifiesta de dotar al complejo residencial que ocupaban de un valor de representación oficial, reconocible esta autoridad a partir de una cuidada arquitectura suntuaria. Estos dos aspectos se alejan de las funciones que podríamos encontrar en una instalación militar corriente, para las que suponemos unas características constructivas mucho más funcionales desde un punto de vista arquitectónico.

Otro aspecto importante que no podemos pasar por alto es la estrecha relación que podemos establecer entre el fin del establecimiento y la fundación de la ciudad romana de Iesso (Guissona), el gran centro urbano situado a tan solo $6 \mathrm{~km}$. Cabe recordar que los niveles fundacionales de la nueva ciudad nos indican una cronología de finales de siglo II a. C. Para nosotros queda clara la relación entre los dos centros, Puig Castellar e Iesso, una tesis que viene apoyada por la cronología y la sucesión seriada de los materiales que hemos podido estudiar en ambos enclaves; de otra manera no se explicaría la fundación de una ciudad como Iesso en fechas tan tempranas en el lugar privilegiado que ocupa en el centro de la rica y productiva plana de Guissona.

Para reforzar más esta conclusión cabe destacar que la fortificación de Puig Castellar muestra indicios suficientes que permiten asegurar que en su momento final, previo al abandono definitivo, se procedió a un desmontaje o destrucción intencionada de las instalaciones, una práctica ya conocida que habitualmente llevaba a cabo el ejército romano para evitar posibles 
reocupaciones de instalaciones estratégicas abandonadas por parte de un enemigo potencial. En este caso estamos frente un abandono planificado del establecimiento, realizado de manera ordenada, hecho que justificaría la ausencia de algunos materiales; en este marco, todo aquello que fuera susceptible de ser reutilizado ya no aparece en el registro arqueológico recuperado. Un ejemplo claro de esta acción lo observamos en las pocas tejas documentadas o en la gran habitación núm. 9, destruida por un incendio que intuimos quizás fuera intencionado, puesto que no conservaba en su interior casi ningún objeto aprovechable. Las evidencias indican que una vez se hubo vaciado el establecimiento y recuperado todo lo que podía tener algún valor (vajillas, armamento, tejas) se procedió al derribo de las dependencias que aún se mantenían en pie. Una prueba fehaciente de este proceso lo documentamos en el relleno de la cisterna, depósito donde se arrojaron paredes enteras de adobes y sus revestimientos. No podemos descartar que fuera durante este proceso de desmantelamiento general cuando desparecieron las piedras que faltan en los zócalos y cimientos de algunas paredes, así como la destrucción parcial de las defensas (muralla y torres). Este aspecto es, hoy por hoy, difícil de contrastar ya que también se pudo haber producido en un lapso de tiempo más amplio, por ejemplo, cuando se erigió la extensa villa romana de Sant Pelegrí, ubicada a menos de $300 \mathrm{~m}$, cuya primera fase ya se documenta a mediados de siglo I a. C. Su construcción muy bien podría haber promovido estas acciones de expolio de bloques tallados en la cercana fortificación abandonada.

A pesar de tratarse de unas primeras conclusiones, pensamos que el establecimiento de Puig Castellar, junto a su papel estrictamente militar podría haber funcionado también como sede oficial de un centro romano de administración territorial, al menos en algún momento avanzado de su breve existencia, que recordemos llegó a poco más de medio siglo (180-120 a. C.). Tomando en consideración esta función, no resultaría extraño encontrar a altos funcionarios de la administración romana viviendo y desarrollando su actividad en el interior de estas instalaciones militares, unos delegados del poder romano que no descartamos que formaran parte del mismo estamento militar. Pensamos que para llevar a cabo estas funciones organizativas y de planificación era necesario asegurarse una presencia directa sobre el territorio y, en definitiva, serían estos representantes del poder romano los que dejaron su huella en el asentamiento, a través de los detalles suntuarios que muestra la arquitectura y de algunos de los productos consumidos.

Finalmente queremos hacer una última reflexión. Recogiendo la última hipótesis que acabamos de formular sobre la posible presencia en Puig Castellar de un centro administrativo para organizar el territorio y planificar su inmediata colonización, no creemos que esta función tuviera una cronología tan temprana como la que nos da el momento inicial del establecimiento (circa 180 a. C.) y la estratigrafía asociada con el momento de construcción del edificio principal no es suficientemente significativa para poder afirmarlo. Actualmente se piensa que esta política de organización territorial no fue anterior a mediados de siglo II a. C.; con esta premisa todo parece indicar que el establecimiento surgió inicialmente con una clara función de castellum militar y, sin dejar de ejercer esa función, acabó convirtiéndose también, unos decenios más tarde, en la sede de un centro de representación del poder y de organización del territorio. Esta doble función pensamos que justificaría la residencia suntuaria en su interior; por lo tanto, las dependencias nobles dotadas de un cierto lujo y confortabilidad muy bien podrían pertenecer a este segundo momento, aprovechando la protección que les ofrecían las sólidas instalaciones del castellum, y los suministros básicos necesarios y regulares que les proporcionaba la presencia militar. Desgraciadamente, el grado de arrasamiento que muestran las zonas excavadas hasta ahora no nos permiten reconocer estos dos momentos y, por tanto, quedan de momento en el campo de las hipótesis plausibles. 


\section{BIBLIOGRAFÍA}

Asensio, D.; Cardona, R.; Morer, J.; Pou, J.; Gil, B.; Cantero, F. J. y Sànchez, L. (2014): «Novetats de la recerca en els nuclis lacetans de Castellvell (Olius) i Sant Miquel de Sorba (Montmajor). Les campanyes del 2011 al 2013», II Jornades d'Arqueologia de la Catalunya Central 2012. Actes (Vic, 13-15 diciembre 2012). Barcelona, Generalitat de Catalunya. Departament de Cultura; Museu Episcopal de Vic: 104-110.

Boleda, R. (1976): Carta arqueològica de les valls del riu Corb, Sió i Llobregós. Lleida, Institut d'Estudis Ilerdencs.

Camps, E. (1960): «La plana de Guissona: una comarca arqueològica». Ilerda, XXIV.

Carreras, C.; Martin, A.; Pera, J. y Rodrigo, E. (2016): «Las ánforas de Brindisi en la Hispania Citerior. Pautas de distribución y consumo». Saguntum, 48 (4): 87-104.

Casas, J.; Nolla, J. M.; Palahí, Ll.; Vivó, D. y Soler, V. (2015): «Mas Gusó: una statio romana al suburbium d'Emporiae (Provincia Hispania Citerior)». Revista d'Arqueologia de Ponent, 25: 245-262.

Cormack, I.; Loza, P; Sarrado, Ll.; Tomás, S.; Amat, I.; Torner, Ll.; Artigas, D.; Guitart, J.; Pera J. y Ros, J. (2007): «Lost writing uncovered by laser two-photon fluorescence provides a terminus post quem for Roman colonization of Hispania Citerior».. Journal of Archaeological Science, 34 (10): 1594-1600.

Díaz, M. y Ramírez, R. (2015): «El asentamiento militar de Puigpelat (Alt Camp, ager tarraconensis), un castellum tardorrepublicano en tierras tarraconenses». Revista d'Arqueologia de Ponent, 25: 263-278.

Guitart, J.; Pera, J. y Carreras, C. (1998): «La presència de vi itàlic a les fundacions urbanes del principi del segle I aC a l'interior de Catalunya: l'exemple de Iesso», II Col·loqui Internacional d'Arqueologia Romana. El vi a l'antiguitat (Badalona, 6-9 mayo 1998). Badalona, Museu de Badalona: 39-65.

Molist, N. (coord.) (2008): La intervenció al sector 01 del Conjunt Històric d'Olèrdola. De la prehistòria a l'etapa romana (campanyes 1995-2006). Monografies d'Olèrdola, 2. Barcelona, Generalitat de Catalunya; Departament de Cultura.

Morillo, A. (2016): «Campamentos y fortificaciones tardorrepublicanas en Hispania», J. Pera y J. Vidal (eds.), Fortificaciones y control del territorio en la Hispania Republicana. Zaragoza, Ed. Pórtico: 1-52

Morillo, A. y Adroher, A. (2014): «Modelos de arquitectura defensiva e implantación territorial de los campamentos republicanos en Hispania», R. Mataloto, V. Mayoral y C. Roque (eds.), La gestación de los paisajes rurales entre la Protohistoria y el periodo romano. Formas de asentamiento y procesos de implantación. Anejos Archivo Español de Arqueología, LXX. Mérida, CSIC: 227-252.

Olcese, G. (2012): Atlante dei siti di produzione ceramica (Toscana, Lazio, Campania e Sicilia). Roma, Quasar.

Pera, J. (1993) : La romanització a la Catalunya interior. Estudi històric-arqueològic de Iesso $i$ Sigarra $i$ el seu territori. Tesis doctoral. Edición microficha. Bellaterra, Universitat Autònoma de Barcelona.

Pera, J.; Carreras, C; Romaní, N.; Rodrigo, E.; Padrós, N. y De Solà, G. (2016): «El proceso de implantación romana en el NE de la Provincia Citerior en el siglo II a.C.», J. Pera y J. Vidal (eds.), Fortificaciones y control del territorio en la Hispania Republicana. Zaragoza, Ed. Pórtico.

Pita, R. (1954): «Datos provinciales arqueológicos V». Ilerda, XVIII: 14.

Principal, J.; Camañes, M. P. y Padrós, C. (2015): «Un edifici singular al castellum de Monteró 1 (Camarasa, La Noguera), i l'urbanisme complex d'un post avançat del nord-est de la Citerior». Revista d'Arqueologia de Ponent, 25: 309-328.

Ramon, J. (1995): Las ánforas fenicio-púnicas del Mediterráneo central y occidental. Instrumenta, 2. Barcelona, Universitat de Barcelona; Publicacions; Eivissa, Consell Insular d'Eivissa i Formentera. Conselleria de Cultura, Educació i Patrimoni.

Rodà, I.; Àlvarez, A.; Gutiérrez, A. y Royo, H. (2013a): Informe de l'anàlisi d'un fragment de paviment i d'una mostra de material lític procedents del jaciment arqueològic de Puig Castellar de les Guixeres (Biosca, La Segarra). Informe de la Unitat de Arqueometria del ICAC inédito. Tarragona, Institut Català d'Arqueologia Clàssica.

Rodà, I.; Àlvarez, A.; Gutiérrez, A. y Royo, H. (2013b): Informe de l'anàlisi de quatre fragments de paviment trobats al jaciment arqueològic de Puig Castellar de les Guixeres (Biosca, La Segarra). Informe de la Unitat d'Arqueometria del ICAC Tarragona, Institut Català d'Arqueologia Clàssica. 
Rodrigo, E. (2006): L'evolució del poblament de l'ager de Iesso, de l'època ibérica a l'antiguitat tardana. Estudi de l'ocupació i estructuració del territori. Tesis doctoral. Edición en red. Bellaterra, Universitat Autònoma de Barcelona.

Rodrigo, E.; Garcia, G.; Mercado, M. y Guitart, J. (2013): «El jaciment de Can Tacó (Montmeló i Montornès del Vallès) i els inicis de la presència romana al territori laietà en època republicana», M. Prevosti, J. López y J. Guitart (eds.), Ager Tarraconensis, 5. Actes del Simposi internacional (Tarragona, 27-28 octubre 2010). Documenta, 6. Tarragona, Institut Català d'Arqueologia Clàssica; Institut d'Estudis Catalans: 219-232.

Rodrigo, E.; Pera, J.; Carreras, C.; Romaní, N.; Padrós, N. y Guitart, J. (2014): «El proceso previo a la fundación de las ciudades romanas en el NE de la Hispania Citerior: Los ejemplos de Can Tacó y Puig Castellar», Atti IV Convegno Internazionale di Studi Veleiati (Veleia-Lugagnano Val d'Arda, 20-21 septiembre 2013). Bologna, Antequem: 405-418.

Rovira, J. (1979): «Notes d'arqueologia de Catalunya. Les Guixeres de Talteüll». Butlletí Informatiu de l'Institut de Prehistòria i Arqueologia de la Diputació de Barcelona, 31 (set.-des.): 219.

Recibido: 24-04-2018

Aceptado: 27-05-2019 